\title{
El antiguo Díolkos de Corinto. Análisis de las propuestas sobre su trazado y cálculo de trayectoria óptima
}

\section{The ancient Diolkos of Corinth. Analysis of the proposals for its route and calculation of the optimal trajectory}

\author{
PERE GARCÍA RUIZ \\ Universitat Autònoma de Barcelona \\ Pere.GarciaR@e-campus.uab.cat
}

Resumen: En nuestro artículo nos proponemos una reinterpretación del trazado del antiguo Díolkos de Corinto desde una perspectiva científica y rigurosa. Con las herramientas informáticas actuales y la cartografía de la región del Istmo anterior a la apertura del canal, hemos elaborado un conjunto de programas que nos permiten evaluar los posibles trayectos aportados por los estudiosos del tema y, además, elaborar una propuesta de trayectoria óptima.

En nuestro trabajo pensamos que el hecho de abordar el estudio de esta ruta desde el punto de vista de la física y la ingeniería puede aportar una visión complementaria y enriquecedora a los trabajos históricos y arqueológicos, basados exclusivamente en las fuentes históricas. Esperamos que nuestra contribución sea de utilidad a la hora de evaluar los requerimientos técnicos y las dificultades del traslado de embarcaciones entre los golfos del Istmo de Corinto, así como profundizar en el interés económico y estratégico de esta famosa vía.

Palabras clave: Corinto, Istmo, Díolkos, transporte de barcos por vía terrestre.

Abstract: In this paper, we propose a reinterpretation of the itinerary of the ancient Diolkos of Corinth based on a scientific and rigorous perspective. Using the computer tools currently available and the cartography of the Isthmus region prior to the opening of the canal, we have developed a set of programs that allow us, first of all, to evaluate the trajectories proposed by the scholars and, in addition, to elaborate a hypothesis of an optimal trajectory.

In our research, we believe that approaching the study of this trajectory from the point of view of physics and engineering can provide a complementary and enriching vision of the various existing papers about the subject, based exclusively on historical sources. We hope that our contribution could be useful to understand the technical requirements

Recibido: 3 de agosto de 2020; aceptado: 18 de febrero de 2021; publicado: 31 de marzo de 2021.

Revista Historia Autónoma, 18 (2021), pp. 13-41

e-ISSN: 2254-8726; https://doi.org/10.15366/rha2021.18.001 
and the difficulties of the transport of ships between the gulfs of the Isthmus of Corinth, and to evaluate the economic and strategic interests of this famous route.

Keywords: Corinth, Isthmus, Diolkos, inland transport of ships.

\section{Introducción}

La estrecha franja de tierra que conecta el Peloponeso con la Grecia Central, conocida como Istmo de Corinto, ha sido desde tiempos remotos un punto de gran valor estratégico y comercial. La ciudad de Corinto, con dos puertos importantes a ambos lados del Istmo, ante la imposibilidad de realizar un canal que conectara los dos golfos, optó por unirlos mediante una calzada pavimentada que permitiera el tránsito fluido de mercancías y, en determinados casos, los mismos barcos. Este camino se conoce como Díolkos ( $\Delta$ ío $\lambda \kappa o \varsigma)$ y se remonta a la época del tirano Periandro (c. 600 a. C.).

Tal como hemos expresado brevemente en el resumen inicial, el presente artículo propone una reinterpretación del trazado del antiguo Díolkos de Corinto desde la perspectiva de la ingeniería. Para llevar a cabo nuestro objetivo hemos empezado por determinar la longitud real del canal de Corinto y elaborar un mapa calibrado de la zona, con los datos más precisos posibles respecto al relieve original de la región en la época de la construcción de la vía.

La primera parte del trabajo se dedica a evaluar las propuestas que han hecho diversos autores sobre el recorrido global del Díolkos. Para analizarlas y compararlas en términos de viabilidad y de facilidad de tránsito de buques y mercancías, hemos desarrollado un conjunto de programas informáticos que, a partir de la cartografía informatizada del relieve de la zona, nos aportan mucha información sobre las fuerzas y el trabajo físico necesarios para el desplazamiento de cargas a lo largo de los recorridos propuestos. Cabe destacar el valor añadido que representan la informática, la física y la ingeniería a la hora de abordar el estudio de esta vía, ya que aportan una visión complementaria y enriquecedora de los trabajos existentes, basados exclusivamente en fuentes históricas. En segundo lugar, aprovechamos el software realizado para elaborar una hipótesis de trayectoria óptima, que hemos llevado a cabo mediante una técnica de optimización de recorridos, basada en algoritmos genéticos.

Esperamos que esta contribución sea de utilidad a la hora de abordar de manera rigurosa diversos aspectos sobre la topografía de la zona, así como la elaboración de una propuesta de trayecto que en el futuro sea factible de contrastar con hallazgos arqueológicos. También deseamos que aporte algo de luz sobre las dificultades físicas y técnicas a la hora de mover 
mercancías e, incluso, barcos de una cierta envergadura, entre los golfos del Istmo de Corinto, todo ello haciendo énfasis en el interés económico y estratégico de esta famosa vía pavimentada.

\section{El relieve del Istmo de Corinto en tiempos históricos}

A la hora de emprender el estudio de la posible trayectoria del Díolkos, la primera dificultad que encontramos es la de determinar con precisión el relieve original de la zona del Istmo en tiempos clásicos.

En efecto, las actuaciones llevadas a cabo durante el período de apertura del moderno canal de Corinto (1881-1893), así como las posteriores alteraciones que han convertido la región en un importante nudo de comunicaciones y centro logístico e industrial, han cambiado de manera radical la topografía de la zona, por lo que solo se parece a la original en sus rasgos más generales.

Para realizar cálculos sobre el posible recorrido original del Diolkos hay que contar con datos precisos del relieve del Istmo con la mayor aproximación posible a la configuración que poseía antes de las actuaciones descritas. Debemos remontarnos a la época inmediatamente anterior a la apertura del canal, cuando Corinto era una modesta villa de unos 4000 habitantes y la zona presentaba pocos cambios topográficos respecto a la época en que el Díolkos conectaba los dos golfos.

Para obtener un mapa lo más fiel posible del relieve antiguo del Istmo hemos partido de la carta geográfica de la región realizada por el cartógrafo Charles Muret (1839-1921), elaborada a partir de los datos del ingeniero jefe del canal, Béla Gerster (1850-1923).

Lo que hace especialmente interesante este mapa es la información relevante que contiene acerca de las curvas de nivel del terreno de la zona. Estos datos, procesados de manera adecuada, nos permitirán calcular la altura del territorio con gran precisión. Con herramientas informáticas adaptadas al cálculo de trayectorias óptimas, analizaremos las propuestas que los estudiosos del tema han hecho sobre la trayectoria del Díolkos así como propondremos una nueva, calculada con algoritmos genéticos de optimización de rutas. 
Figura 1. Mapa de la zona de Corinto (Gerster - Muret)

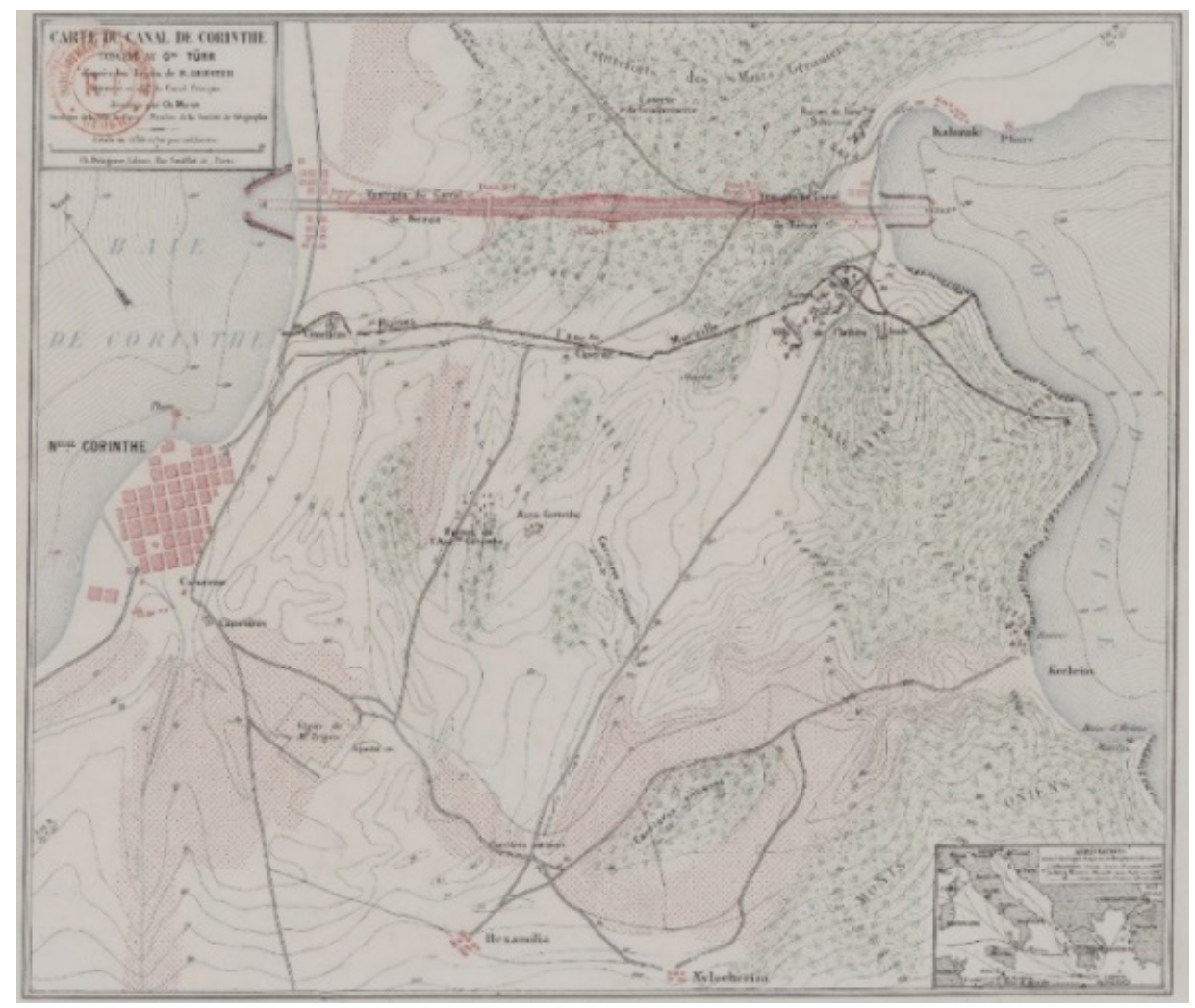

Fuente: Mapa obtenido en la página web de la Biblioteca Nacional de Franciaํ․

Una dificultad adicional del trabajo con mapas digitales es la distorsión provocada por el proceso de escaneo que hace que, a la hora de medir distancias, nos encontramos con notables discrepancias. Así, para trazar y analizar trayectorias sobre el Istmo de Corinto, es esencial disponer de un mapa calibrado de la zona.

Para ilustrar estas distorsiones y elaborar una propuesta para subsanarlas, basta con aplicar la escala de la parte superior izquierda del mapa y trasladarla a la longitud excavada del canal, entre costa y costa:

Mapa original de Charles Muret: 5570 m, mapa de la monografía Corinth 1932²: 5286 m.

Así, es necesario conocer con precisión la longitud real del canal para poder aplicar factores de corrección al mapa elegido y calibrarlo.

\footnotetext{
${ }^{1}$ Gallica. «https://gallica.bnf.fr/ark:/12148/btv1b8438935p/f1.item.zoom»

${ }^{2}$ Fowler, Harold North y Richard Stillwell, Corinth, volume I: Introduction, Topography, Architecture. Harvard University Press, Cambridge, Massachusetts, 1932, p. 58. https://doi.org/10.2307/4390633
} 
3. ¿Cuánto mide realmente el Canal de Corinto?

Una pequeña investigación para averiguar la longitud real del canal de Corinto nos revela una enorme disparidad de datos, que pueden variar entre 6000 y $6400 \mathrm{~m}$ según la fuente consultada. Se trata de diferencias considerables que se deberían evitar.

Figura 2. Monumento en memoria de los ingenieros húngaros Béla Gerstere István Türren el mirador de la parte continental del canal, en la carretera nacional Atenas-Corinto.

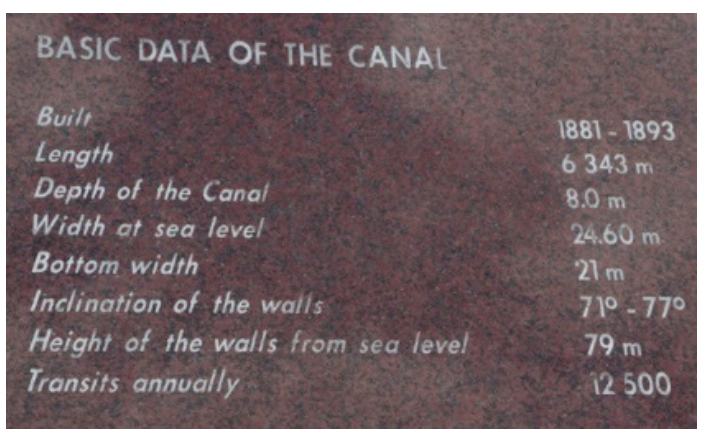

Fuente: fotografía del autor.

El valor más común que observamos es de $6343 \mathrm{~m}$, que probablemente proviene de la longitud entre los extremos de los muelles del mapa original de Charles Muret, tal como queda reflejado en el monumento conmemorativo del mirador del canal (fig. 2), lugar frecuentado por los viajeros y parada obligada en los circuitos turísticos que, desde Atenas, se adentran en el Peloponeso.

Este primer valor ya es erróneo y deriva de una premisa que se presta a confusión. En efecto, la cifra de $6343 \mathrm{~m}$ reúne tanto la distancia de la obra de apertura del canal en el Istmo como la longitud de los muelles auxiliares en ambas costas. Como las instalaciones anexas pueden variar en longitud, mientras que la sección en tierra firme permanece siempre constante, creemos que, al plantear las actuaciones para abrir el canal, la longitud correcta sería la correspondiente a la apertura del Istmo como tierra firme. 
Tabla 1. Datos GPS de las posiciones a evaluar

\begin{tabular}{|c|c|c|c|}
\hline & $\begin{array}{c}\text { Conrdenadas en_grados, } \\
\text { minutos y segundos }\end{array}$ & $\begin{array}{c}\text { Conrdenadas_en_grados } \\
\text { decimales } \\
\end{array}$ & Conrdenadas en radianes \\
\hline \multirow{2}{*}{$\begin{array}{c}\text { Entrada Golfo de } \\
\text { Corinto } \\
\end{array}$} & $37^{\circ} 57^{\prime} 053^{\prime \prime} \mathrm{N}$ & 379514722 & 06623781458690959349 \\
\hline & $22^{\circ} 57^{\prime} 349^{\prime \prime} \mathrm{E}$ & 22959694444444444 & 04007222633074058582 \\
\hline \multirow{2}{*}{$\begin{array}{c}\text { Entrada Golfo } \\
\text { Sarónico } \\
\end{array}$} & $37^{\circ} 54^{\prime} 588^{\prime \prime} \mathrm{N}$ & 379163333 & 0.6617648563685668994 \\
\hline & $23^{\circ} 000^{\prime} 36^{\prime \prime} \mathrm{E}$ & 23009333333333334 & 04015886253555486184 \\
\hline
\end{tabular}

Para calibrar el mapa de trabajo se ha considerado que la mejor opción era tomar las coordenadas GPS de los dos extremos del Istmo, sin tener en cuenta los muelles anexos; y calcular la distancia real entre ellos mediante fórmulas de trigonometría esférica. Con un aparato GPS se tomaron los datos de la tabla 1, con una precisión de una décima de segundo de arco (error máximo de 3-4 m). Con estos datos se obtiene la longitud del Canal de Corinto con un error aproximado del $1 \%$, es decir, como máximo, de un metro por kilómetro.

Para el cálculo de la distancia en cuestión emplearemos la fórmula Harvesine para la aproximación esférica de la distancia (d) entre dos puntos de la superficie terrestre:

$$
d=2 r \arcsin \left(\sqrt{\sin ^{2}\left(\frac{\varphi_{2}-\varphi_{1}}{2}\right)+\cos \varphi_{1} \cos \varphi_{2} \sin ^{2}\left(\frac{\lambda_{2}-\lambda_{1}}{2}\right)}\right)
$$

$\varphi_{1}, \varphi_{2} \mathrm{i} \lambda_{1}, \lambda_{2}$ son la latitud y la longitud delos puntos 1 y 2 , respectivamente, expresadas en radianes.

$\mathbf{r}$ es el radio terrestre medio: $6371 \mathrm{~km}$.

$\boldsymbol{\varphi}_{1}=0,662378 \boldsymbol{\varphi}_{2}=0,661764 \lambda_{1}=0,400722 \lambda_{2}=0,401588$

Aplicando estos datos a la fórmula: $\quad \mathrm{d}=5,849697795 \mathrm{~km} \approx \mathbf{5 8 5 0} \mathbf{~ m}$

Con esta medida precisa del canal abierto en el Istmo se puede calibrar el mapa digital de la siguiente manera:

La separación de los extremos del canal, en el mapa original, es de 2,629 píxeles. Si queremos adaptarlo a una escala de $2 \mathrm{~m}$ por píxel obtenemos una longitud de $5258 \mathrm{~m}$. Como la longitud real que acabamos de calcular es de $5850 \mathrm{~m}$, basta con redimensionar la anchura por un factor multiplicativo de 1,1126. La escala vertical, tomando medidas entre el teatro de Istmia y el canal, es correcta. Así pues, basta reescalar en horizontal. De esta manera obtenemos un mapa digital calibrado a $2 \mathrm{~m}$ por píxel, apto para realizar cálculos precisos sobre el relieve del Istmo y el recorrido del Díolkos.

Así, concentraremos nuestro trabajo en el área siguiente ${ }^{3}$ :

\footnotetext{
${ }^{3}$ Como el mapa original cubre toda la zona del Istmo, para centrarnos en el área concreta en la que llevaremos a cabo nuestros cálculos delimitaremos nuestra superficie de trabajo, obteniendo una nueva imagen de dimensiones: 3800 píxeles de ancho por 1650 de altura.
} 
Figura 3. Mapa calibrado de la zona del Istmo.

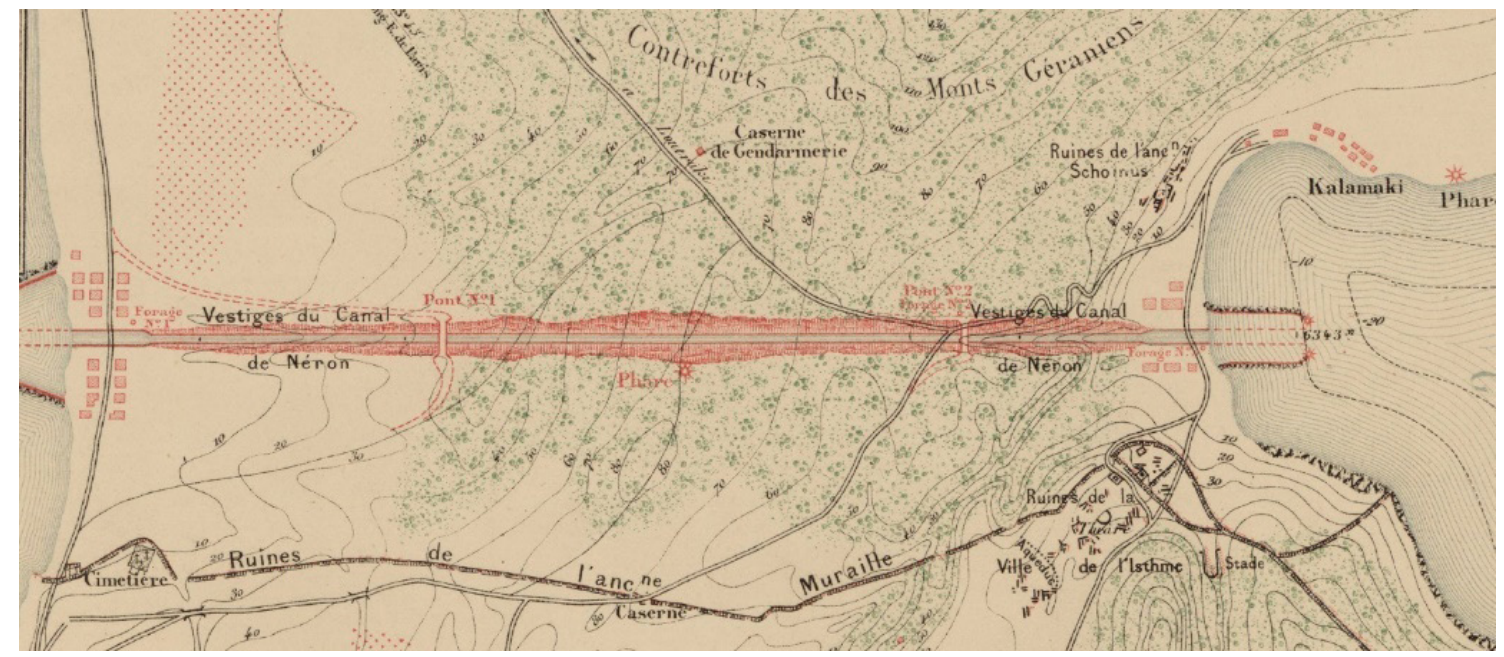

Fuente: Mapa obtenido en la página web de la Biblioteca Nacional de Francia.

La imagen limita al norte con las montañas de la cordillera Gerania, y al sur, con la muralla Hexamilion. La cordillera de las montañas Oneia, en el sureste del territorio y por debajo de la muralla, no se tendrá en cuenta.

\section{Cálculo del relieve del Istmo}

Una vez aislada la sección cartografiada del Istmo válida para nuestro estudio, necesitamos conocer el relieve de la zona en todos sus puntos. Para obtener estos datos hemos desarrollado un conjunto de programas de ordenador breves e individualizados. Este software se ha realizado en lenguaje Python (versión 2.7), sistema de programación de alto nivel y propósito general.

\subsection{Tratamiento de las imágenes ${ }^{4}$}

Como el trazado de la muralla Hexamilion marca uno de los límites inferiores del Díolkos, se pueden ignorar algunas curvas de nivel situadas por debajo de estas fortificaciones, ya que no intervendrán en los cálculos.

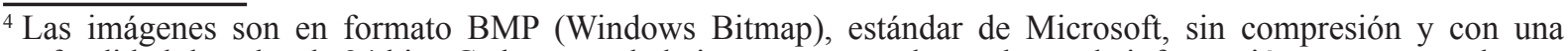
profundidad de color de 24 bits. Cada punto de la imagen consta de tres bytes de información, uno para cada uno de los colores primarios: rojo, verde y azul.
} 
Las actuaciones sobre la imagen se han realizado con Microsoft Paint, programa presente en todas las versiones de Microsoft Windows. Una vez dibujados los límites y las curvas de nivel, el resultado es el siguiente:

Figura 4. Mapa calibrado del Istmo una vez dibujadas las curvas de nivel con colores diversos.

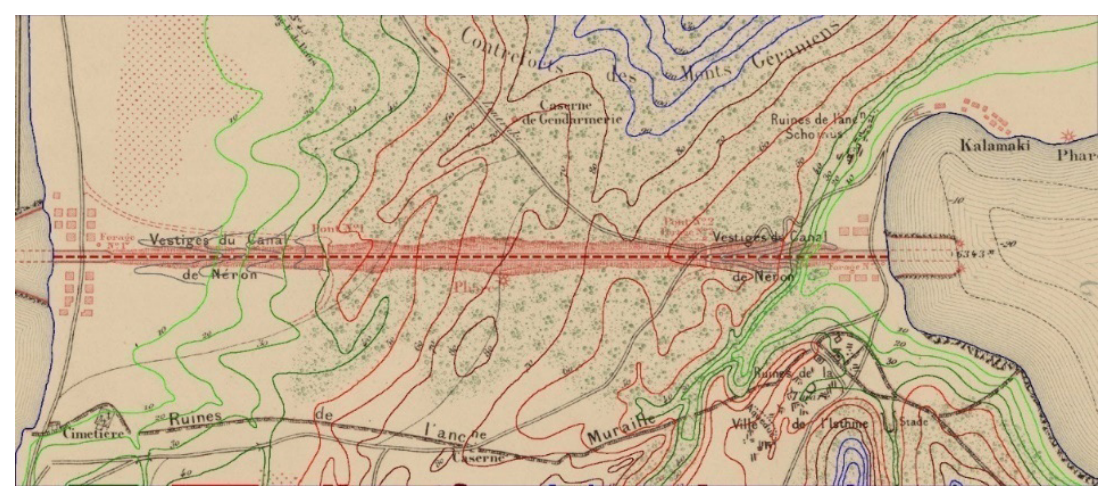

Fuente: Mapa obtenido en la página web de la Biblioteca Nacional de Francia.

Otra versión de la imagen anterior del Istmo contiene el trazado de la muralla Hexamilion y la línea del canal. Esta información se procesa aparte y se añade posteriormente una vez interpolado el relieve de la zona.

Un programa procesa estas dos imágenes tomando los valores relevantes y genera dos nuevas para la siguiente fase. La primera contiene los datos de los límites del mapa, líneas de costa de ambos golfos y curvas de nivel:

Figura 5. Mapa calibrado del Istmo con las curvas de nivel y la línea de la costa

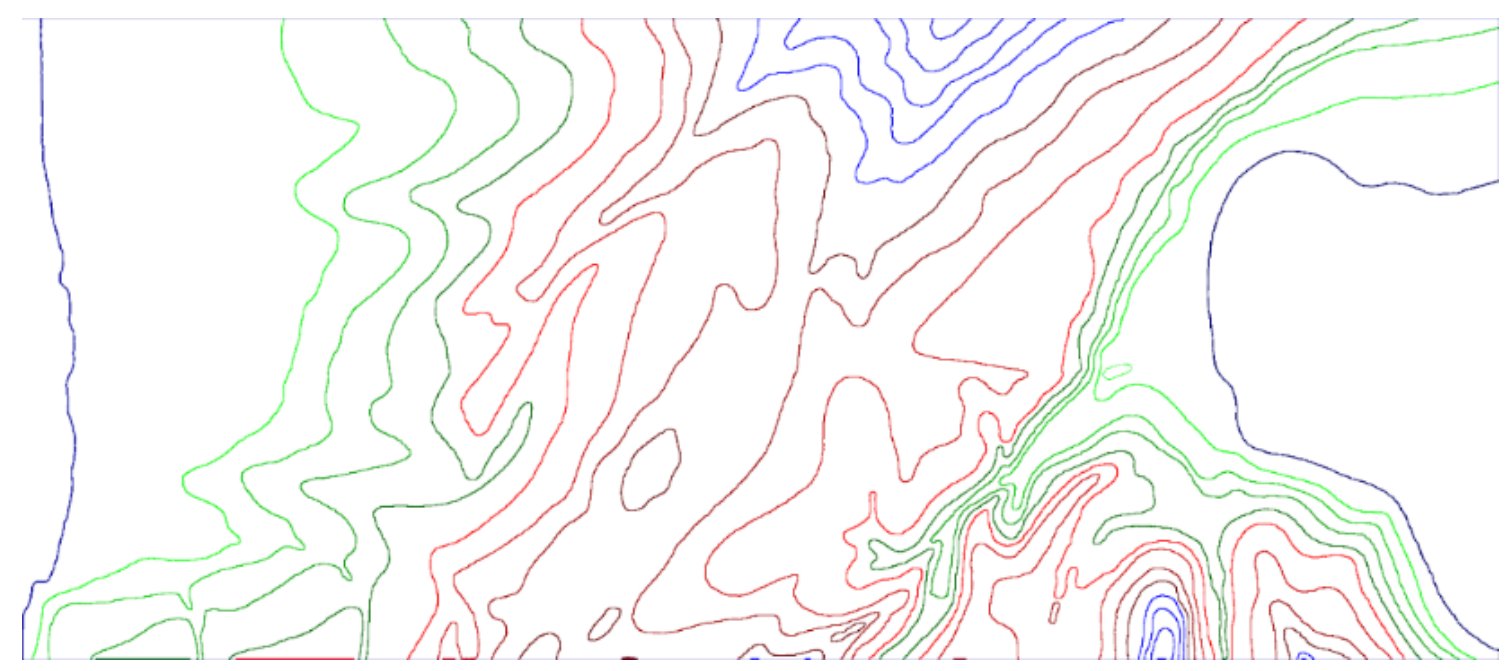

Fuente: elaboración propia.

Para facilitar la identificación visual de las líneas principales del Istmo, elaboramos una imagen adicional con la misma información del mapa anterior pero que, además, incorpora el trazado de la muralla Hexamilion y la línea del canal actual. Como estas líneas pasan por 
encima de las curvas de nivel, esta imagen no es válida para los cálculos sobre el relieve. Tan solo almacena datos adicionales que nos servirán posteriormente.

\subsection{Cálculo de los valores del relieve}

Una vez obtenidas estas imágenes, un programa se encargará de calcular el relieve en todos los puntos del mapa. Obviamente, se trata de una reconstrucción teórica, basada en estimaciones matemáticas a partir de los datos conocidos. Sin embargo, como veremos en las imágenes correspondientes, el resultado será bastante preciso a la hora de realizar hipótesis sobre el trazado del Díolkos, ya que los cálculos de interpolación se basan en criterios geométricos que garantizan el rigor y la precisión de los valores obtenidos.

El sistema de curvas de nivel nos permite representar en un sistema de dos dimensiones o mapa topográfico el relieve de una superficie que en realidad es tridimensional. Para reflejar fielmente las variaciones de altura a lo largo de la superficie objeto de estudio y obtener un relieve suave y uniforme, la interpolación entre curvas de nivel será la media aritmética de diversos valores calculados al examinar la distancia relativa entre cotas adyacentes.

Para aumentar la precisión de las estimaciones obtenidas los cálculos se han realizado en centímetros. Estos datos se guardan en un fichero que contiene los datos de relieve de todos los puntos del mapa. Para realizar otras tareas se crean dos ficheros más que incluyen el trazado de la muralla Hexamilion y la línea del canal ${ }^{5}$.

A partir de los datos obtenidos anteriormente podemos comprobar la sutileza de las interpolaciones generando unos nuevos mapas que nos muestran el relieve de la zona con pseudocolores que varían según la altura y que se han elegido de acuerdo con las convenciones estándar para las representaciones de mapas en altura:

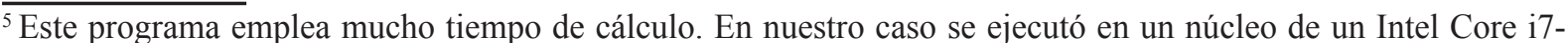
3630 QM a $2.40 \mathrm{GHz}$ y necesitó casi cinco horas para completar la tarea. De todas maneras, este programa solo se ha de ejecutar una vez, ya que las acciones posteriores utilizarán los ficheros de datos generados.
} 
Figura6. Imagen de relieve del Istmo con la línea del canal y el trazado de la muralla Hexamilion.

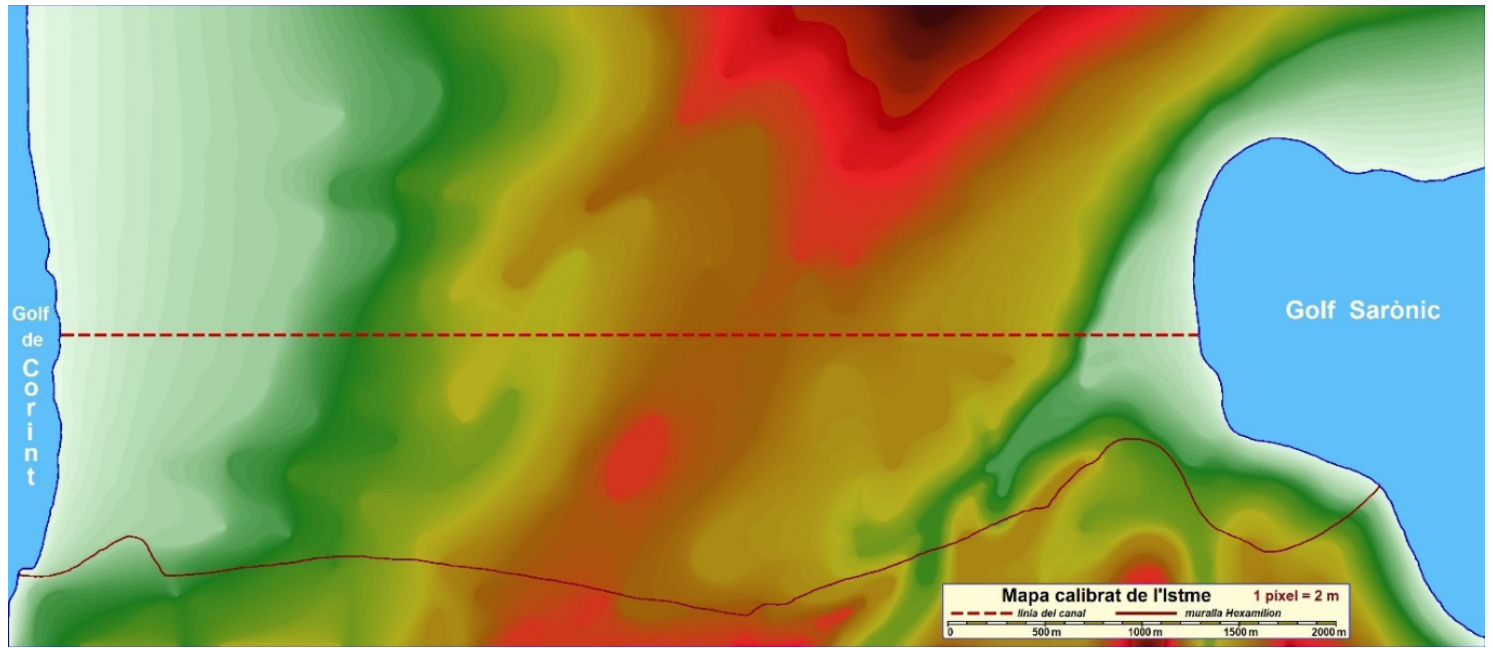

Fuente: elaboración propia.

\section{Análisis de trayectorias sobre el territorio}

Para evaluar trayectorias sobre la zona objeto de estudio basta con tomar una imagen original calibrada y dibujar a mano alzada con Microsoft Paint o con cualquier otro programa de tratamiento de imágenes, la línea del recorrido a analizar:

Figura 7. Ejemplo de trayectoria.

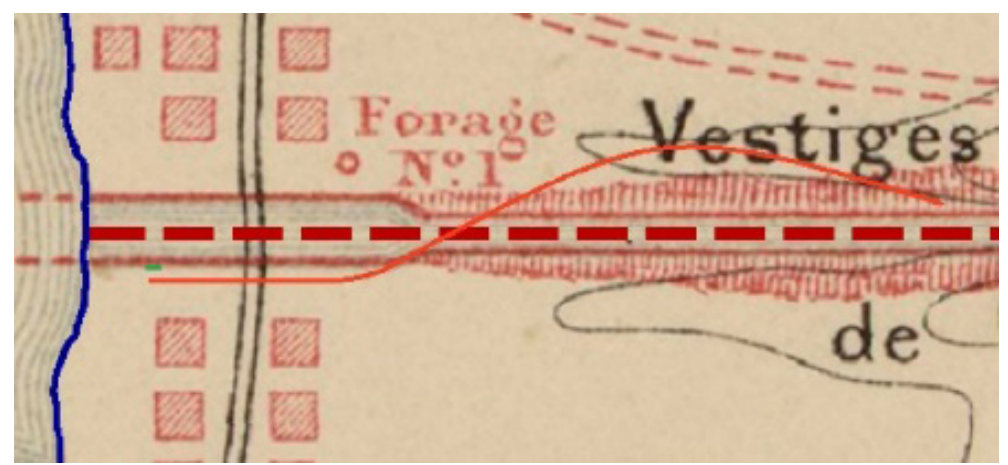

Fuente: Mapa obtenido en la página web de la Biblioteca Nacional de Francia.

La combinación de dos programas breves se encarga de procesar la trayectoria a evaluar y generar tres ficheros de resultados: una imagen con la misma trayectoria, dibujada sobre un mapa del relieve, otra con la sección transversal del perfil del trazado, y un archivo de texto con los datos resultantes del análisis realizado como: cotas y pendientes máximas y mínimas, 
inclinaciones por tramos, longitud del trayecto, porcentajes de pendientes por intervalos, etc. De esta manera analizaremos las propuestas que los estudiosos del Díolkos han realizado sobre su recorrido y comprobaremos la eficacia de nuestro trabajo.

A la hora de interpretar los resultados debemos tener en cuenta varias consideraciones:

a) Las trayectorias deben ser el máximo de rectas posible y presentar un amplio radio de curvatura en las secciones sinuosas que se adaptan a las irregularidades del terreno.

Según las fórmulas geométricas aplicadas al trazado de curvas en el diseño de carreteras ${ }^{6}$, para un barco como el trirreme, de $36 \mathrm{~m}$ de eslora y $5 \mathrm{~m}$ de manga, si queremos que el casco se ubique dentro del trazado de la ruta, el radio de curvatura debe ser, como mínimo, de siete veces la longitud de la nave, estimada en unos $36 \mathrm{~m}$. Así evaluamos el radio de curvatura mínimo de la calzada en $250 \mathrm{~m}$. Cualquier valor inferior dificulta la maniobra de transporte del barco provocando que una parte del casco exceda los límites de la vía. Este parámetro es especialmente interesante a la hora de evaluar las posibles trayectorias del Díolkos a lo largo del Istmo, ya que se trata de una restricción fundamental del trazado, que debe ser recto o con curvas muy amplias y suaves.

Figura 8. Diagrama del radio de curvatura.

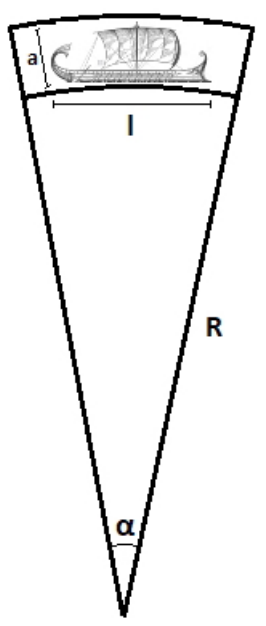

Fuente:

b) Los gráficos correspondientes a las secciones transversales muestran las alturas de la calzada a lo largo de su trayectoria. Los mejores caminos serán aquellos en los que no se observen cambios repentinos de las cotas, ya que, sobre el terreno, esto se traduce en diferencias considerables de pendiente.

Entendemos por pendiente la relación entre la distancia recorrida y la altura ascendida al recorrerla. Este desnivel se puede expresar en porcentaje (\%) o bien en grados $\left({ }^{\circ}\right)$.

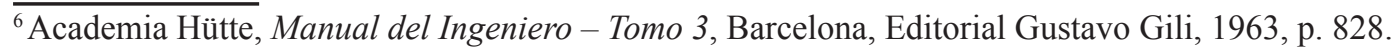


Cuando las rampas presentan inclinaciones suaves, como es el caso de las carreteras, las pendientes se muestran en porcentaje y se calculan según el siguiente criterio:

$$
\text { pendiente en } \%=\frac{\text { altura ascendida } \times 100}{\text { distancia recorrida }}
$$

es decir, los metros que se asciende cada 100 metros recorridos. Evidentemente, a la hora de calcular las fuerzas asociadas al plano inclinado, el uso de operadores trigonométricos hace que las pendientes correspondientes deban expresar en grados (fig. 9).

c) Para evaluar las rutas hemos recurrido a las leyes de la física elemental y hemos calculado la fuerza necesaria para desplazar una tonelada de peso en cada uno de los intervalos, atendiendo a la pendiente correspondiente y hemos determinado el trabajo total realizado para completar el trayecto. Esta magnitud, directamente relacionada con la longitud total del itinerario, nos revela el grado de dificultad que conlleva su elección, así como nos permite comparar las opciones analizadas.

El cálculo de la fuerza se ajusta al esquema vectorial del plano inclinado.

Figura 9. Descomposición de fuerzas del plano inclinado.

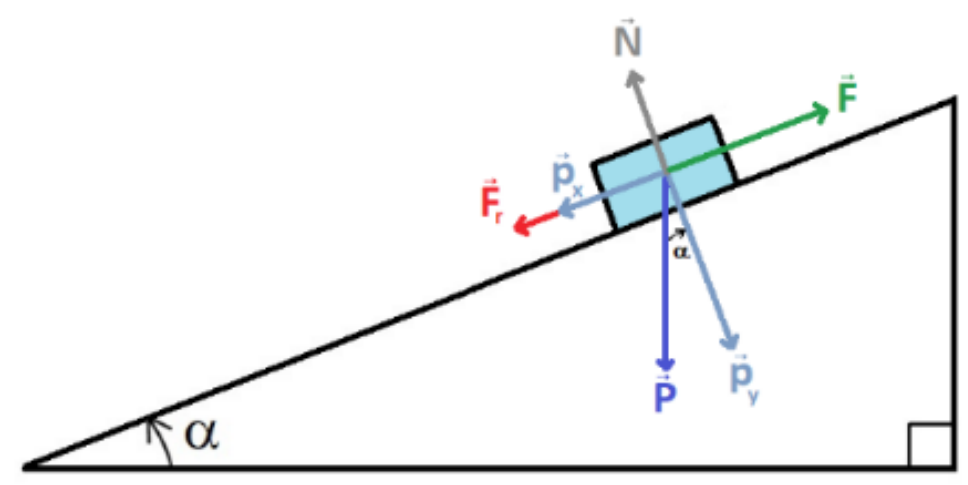

Fuente:

De la aplicación de la segunda ley de Newton al plano inclinado con rozamiento deducimos que la fuerza mínima que se debe aplicar a una masa determinada para moverla de manera uniforme sobre su superficie (sin aceleración) es:

$$
F=m g(\sin \alpha+\mu \cos \alpha)
$$

Donde $m$ es la masa, $g$ la constante de aceleración de la gravedad $\left(9,80665 \mathrm{~m} / \mathrm{s}^{2}\right)$, el coeficiente de rozamiento yel ángulo de inclinación de la pendiente en cuestión. 
En caso de que no haya ninguna pendiente, la fuerza se aplica exclusivamente en el plano horizontal y es directamente proporcional al coeficiente de rozamiento, ya que el ángulo es cero:

$$
F=m g \mu
$$

Según el Sistema Internacional de Unidades, la fuerza se mide en $\mathrm{m} \cdot \mathrm{kg} \cdot \mathrm{s}^{2}$, unidad que recibe el nombre de newton y que se expresa con la letra N. Así, un newton se define como la fuerza que al aplicarse a un cuerpo de un $\mathrm{kg}$ de masa produce una aceleración de un metro por segundo al cuadrado.

Tomaremos 1/35 como valor del coeficiente de rozamiento, estimación media de la cantidad que recomienda el tratado de ingeniería de la Academia Hütte ${ }^{7}$ para el desplazamiento de carros de ruedas metálicas sobre pavimentos de diversos estados. Esto implica una resistencia de 28,6 kg/Tm. De la misma manera, en el momento de evaluar el peso total de la nave a transportar, estimaremos en un $8 \%$ del total de la carga el peso de los dispositivos holkos destinados al transporte de los barcos.

En nuestro caso, en que los desplazamientos se realizan sobre trayectos casi rectilíneos, dada una fuerza constante $\mathrm{F}$, el trabajo $\mathrm{T}$ realizado a lo largo del recorrido se obtiene multiplicando la fuerza por la distancia en metros. Así calcularemos los trabajos parciales sobre cada uno de los intervalos, según las pendientes correspondientes, para obtener la magnitud del trabajo necesaria para el desplazamiento de cargas a través del Díolkos: $T=F \cdot S$

Donde $F$ es la fuerza a aplicar según la pendiente del intervalo y $s$ la longitud. El resultado se expresa en newtons por metro $(\mathrm{N} \cdot \mathrm{m})$, unidad denominada Joule $(\mathrm{J})$.

A continuación, expondremos las conclusiones a las que hemos llegado tras analizar las rutas propuestas por los diferentes estudiosos del Díolkos en sus trabajos. Comenzaremos analizando el trayecto conocido de la vía.

\subsection{Trayecto conocido del Díolkos}

Corresponde a los tramos visibles en la actualidad, con la conexión correspondiente a la parte destruida por la apertura del canal. La siguiente imagen de Google Earth ${ }^{8}$ nos aporta una visión ampliada de la zona. A unos $10 \mathrm{~m}$ de la rampa de la sección inicial, la vía progresa de manera rectilínea hacia el sureste (en la fig. 10, hacia la derecha), desaparece brevemente debido a la carretera que lleva al puente sumergible del lado de Loutraki, y continúa por unas decenas de metros trazando una curva de $250 \mathrm{~m}$ de radio. Este tramo se interrumpe bruscamente cuando llega al canal, para continuar en el otro lado, dentro de los terrenos de la Escuela Militar de Ingeniería de Loutraki, describiendo otra curva, algo más ancha, de $400 \mathrm{~m}$ de radio. Las dos

\footnotetext{
${ }^{7}$ Academia Hütte, Manual del Ingeniero... op. cit., p. 824.

${ }^{8}$ Imagen obtenida de Google Earth Pro con la herramienta Regla para trazar y medir distancias (29 de junio de 2018).
} 
curvas se ajustan a los requisitos mencionados anteriormente. Al final de esta sección, donde parece que la vía retorna al Peloponeso, se pierde el rastro del Díolkos.

Figura 10. Trayecto conocido del Díolkos.

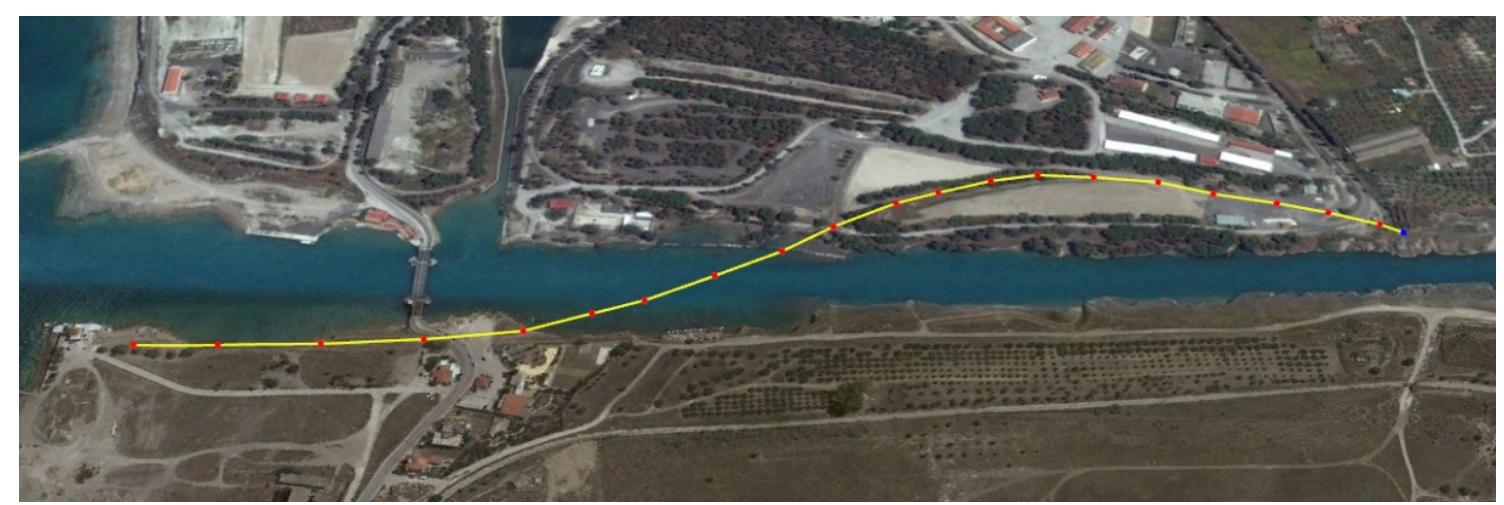

Fuente: Google Earth.

Como podemos ver en el mapa calibrado del relieve (fig. 11), el tramo conocido del Díolkos cubre solo una pequeña parte del Istmo. Las restricciones en las que todos los investigadores coinciden a la hora de proponer un trayecto hipotético son básicamente las siguientes:

a) no puede ir muy al norte, ya que tendría que pasar por colinas de 80 a $130 \mathrm{~m}$ al pie de la cordillera de las montañas Gerania, con pendientes considerables.

b) al sur, la muralla Hexamilion también es uno de sus límites naturales, ya que se supone que se construyó más de cien años después de pavimentar la vía en tiempos del tirano Periandro (ss. VII-VI a. C.). Además, hacia el centro y la parte inferior este del Istmo nos encontramos con las montañas Oneia.

Figura 11. Trayectoria conocida del Díolkos.

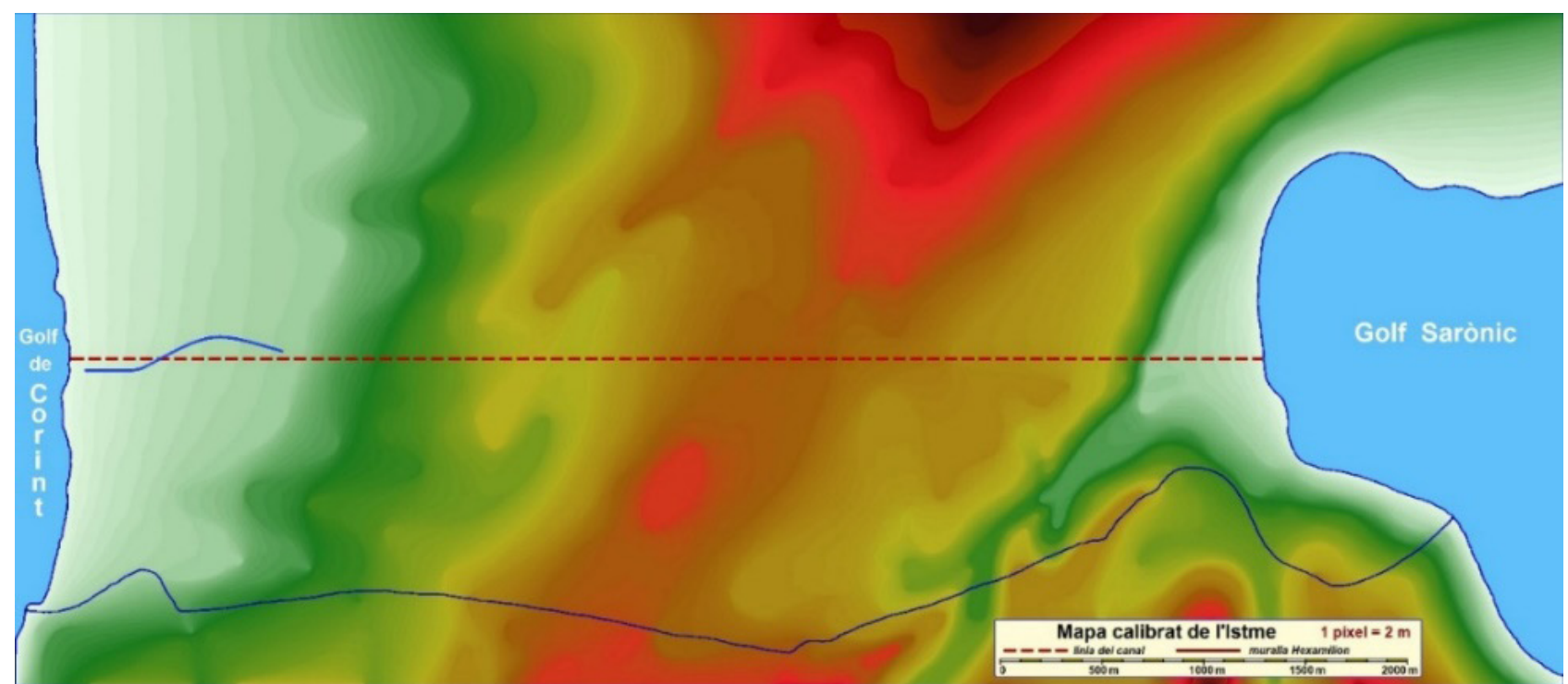

Fuente: elaboración propia. 
Vemos a la izquierda de la imagen la sección conocida del Díolkos, que empieza en el Golfo de Corinto. Tal y como refleja la gráfica de la sección transversal, se trata de un trayecto fácil de recorrer, con pendientes muy suaves, que no llegan al 1,5\% y con amplios radios de curvatura (250 m y $400 \mathrm{~m})$.

Figura 12. Sección transversal del tramo conocido.

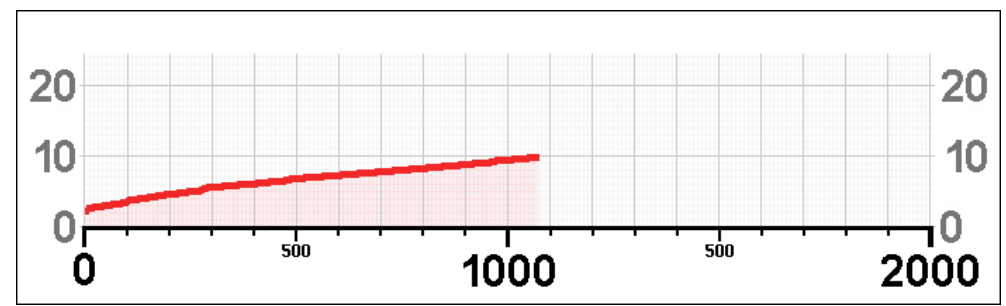

Fuente: elaboración propia.

Como esta parte de la vía es bien conocida, las siguientes rutas propuestas en libros y artículos por los expertos la integran en su recorrido. A partir de su final, al este de la Escuela Militar de Ingeniería de Loutraki, cada autor especula con un trazado diferente a través del Istmo, hasta llegar al puerto de Skinos en el Golfo Sarónico. Las expondremos en orden cronológico, de más antigua a más reciente.

\subsection{Propuesta de Georges Raepsaet (1993) ${ }^{9}$}

En su artículo de 1993 “Le Diolkos de l'Isthme à Corinthe: son tracé, son fonctionnement”, el historiador y arqueólogo belga Georges Raepsaet hace una propuesta muy interesante sobre el recorrido del Díolkos. En la imagen vemos como, tras el tramo conocido de la Escuela Militar de Ingeniería, la vía sigue el canal actual ligeramente por encima, evitando las cotas más altas, hasta su descenso, más bien abrupto, de los marcados desniveles cercanos al Golfo Sarónico.

\footnotetext{
${ }^{9}$ Raepsaet, Georges, "Le Diolkos de l'Isthme à Corinthe: son tracé, son fonctionnement", en Bulletin de Correspondance Hellénique, 117 (1993), p. 234. https://doi.org/10.3406/bch.1993.1679
} 
Figura 13. Trayectoria de Georges Raepsaet (página 234 del artículo).

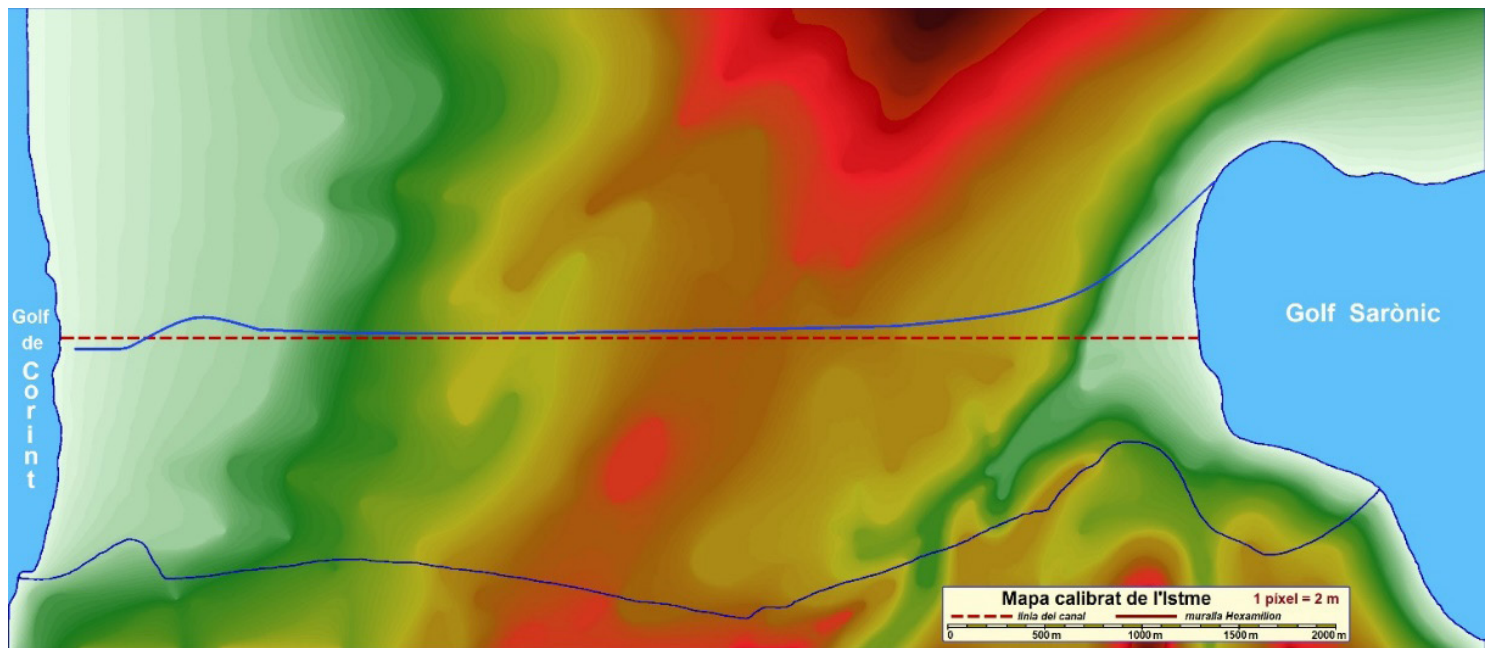

Fuente: elaboración propia.

Figura 14. Sección transversal de la propuesta de Georges Raepsaet.

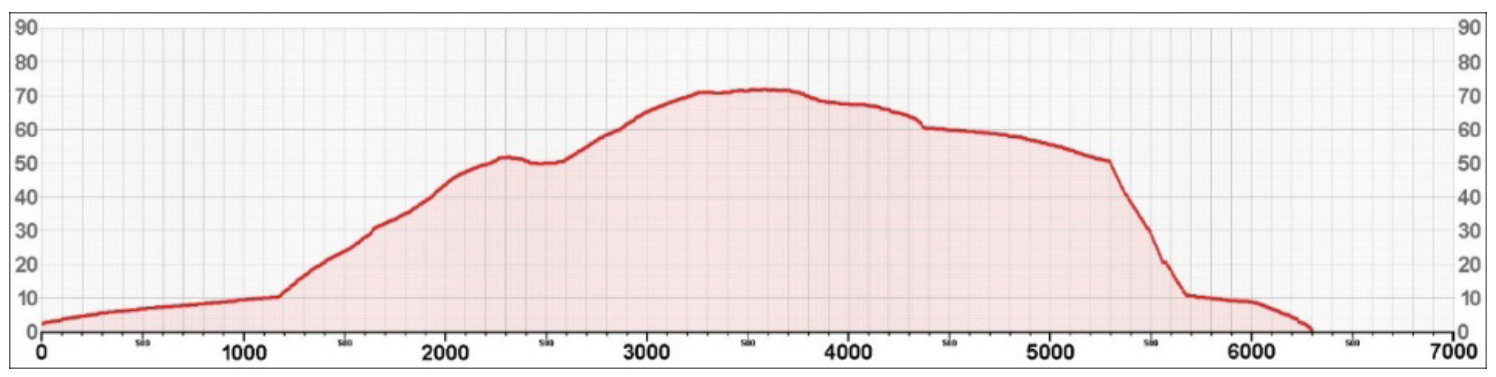

Fuente: elaboración propia.

Se trata de la propuesta más solvente tras la óptima que hemos calculado y que proponemos más adelante. Solo presenta el inconveniente de tener que afrontar varias pendientes pronunciadas al aproximarse al Golfo Sarónico, que no llegan al $15 \%$ y que en el caso más empinado se limitan a unos $125 \mathrm{~m}$.

Punto a favor:

- Recorrido muy corto $(6297,13 \mathrm{~m})$ y económico en términos de trabajo total (3169049.74 J/Tm)

Puntos en contra:

- Trazado bastante abrupto al acercarse al Golfo Sarónico con fuertes pendientes (entre el $5 \%$ y el $15 \%$ en el $5 \%$ del global de la ruta). Cabe destacar que las pendientes con más de un $10 \%$ de desnivel serían excesivas para los vehículos sin frenos. En la gráfica de la sección transversal (fig. 14) vemos que, a partir de los $5300 \mathrm{~m}$ del recorrido, en tan solo $370 \mathrm{~m}$ el desnivel es de $40 \mathrm{~m}$. 
- Una vez superada la sección conocida de la Escuela Militar de Ingeniería, los rastros de Díolkos apuntan a su regreso hacia el Peloponeso, por debajo del Canal. Aunque más adelante vuelva a subir, parece extraño que después de las dos curvas de la parte conocida, la ruta prosiga de forma completamente recta, sin adaptarse mínimamente a las ondulaciones del terreno y así minimizar las pendientes.

\subsection{Propuesta de Walter Werner (1997)}

El artículo del historiador y arqueólogo alemán Walter Werner de $1997^{10}$, tras facilitar información arqueológica sobre las diversas secciones conocidas del Diolkos, nos hace una propuesta original sobre la posible continuación de la vía, que durante un buen tramo se acerca a la muralla Hexamilion.

Figura 15. Trayectoria propuesta por Walter Werner (página 108 del artículo).

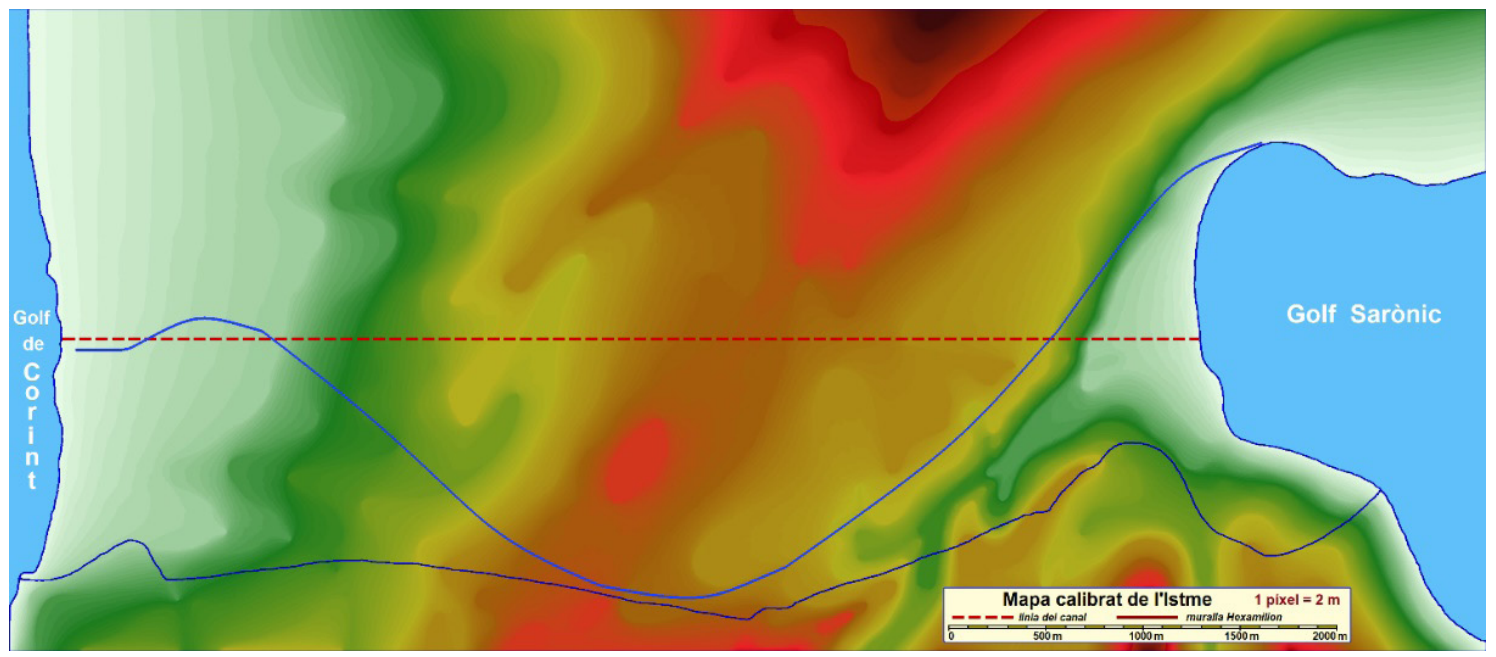

Fuente: elaboración propia.

Figura 16. Sección transversal de la propuesta de Walter Werner.

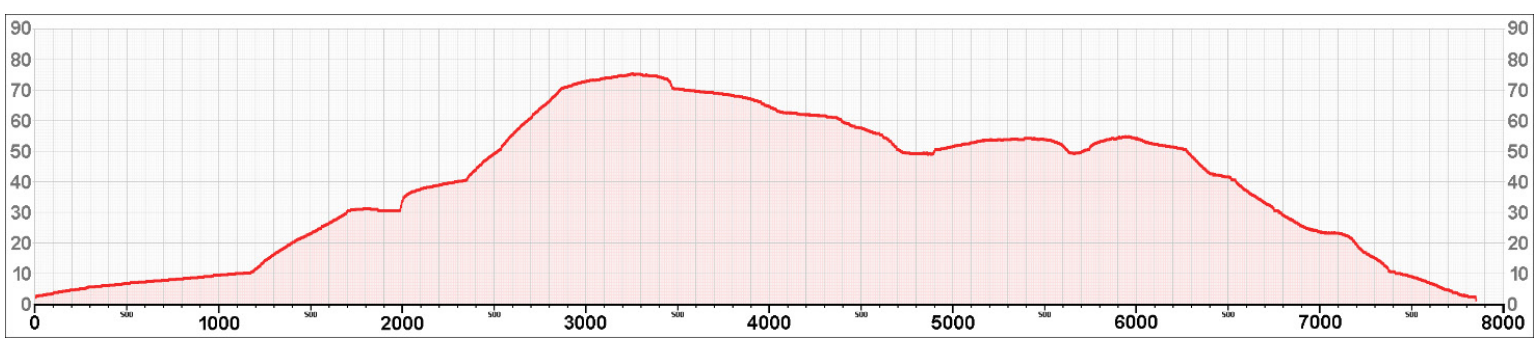

Fuente: elaboración propia.

\footnotetext{
${ }^{10}$ Werner, Walter, "The Largest Ship Trackway in Ancient Times: the Diolkos of the Isthmus of Corinth, Greece, and early attempts to build a canal", en International Journal of Nautical Archaeology, 26 (1997), p. 108. https:// doi.org/10.1111/j.1095-9270.1997.tb01322.x
} 
Es un planteamiento original, probablemente influido por los testimonios de los visitantes del siglo XIX que afirman haber visto vestigios del Díolkos cercanos a la parte central de la muralla Hexamilion. Como la anterior propuesta analizada, también debe afrontar algunas pendientes considerables al llegar al Golfo Sarónico, que no llegan al $15 \%$ y que en el caso más pronunciado comportan unos $43 \mathrm{~m}$.

Punto a favor:

- Recorrido un poco largo pero con una fuerza máxima aplicable contenida (1581.82 N / Tm). El hecho de pasar cerca de la muralla Hexamilion podría conectar la vía con otros caminos vinculados a rutas más directas entre los puertos principales Lequeo y Céncreas.

Puntos en contra:

- Trazado bastante abrupto al acercarse al Golfo Sarónico con fuertes pendientes (entre el $5 \%$ y el $15 \%$ en el 4,1\% del global de la ruta). El trabajo total necesario por tonelada también es elevado (3778995.39 J). Tal y como refleja la gráfica de la sección transversal (fig. 16), los repentinos cambios de pendientes se extienden por todo el recorrido.

- La amplia curva descrita por debajo del actual canal obedece al interés del autor por acercarse a la muralla Hexamilion en su parte central, sin adaptarse a las ondulaciones del terreno. Esto hace que en muchos puntos se deban superar fuertes pendientes.

\subsection{Propuesta de Apóstolos Papafotíou (2007) ${ }^{11}$}

En el libro de Apóstolos Papafotíou: El Díolkosen el Istmo de Corinto, publicado en 2007, el autor hace un estudio de posibles trayectorias del Díolkos, clasificándolas según el grado de dificultad que presentan las pendientes máximas calculadas. Como en nuestro caso, el autor parte de los datos aportados por el mapa de Béla Gerster, según la versión inglesa posterior de 1932 publicada por la American School of Classical Studies de Atenas ${ }^{12}$.

Del texto de Papafotíou se deduce que el estudio del relieve del Istmo ha sido realizado por la Oficina Técnica de Mih. Salakhoris y colaboradores. No se facilita ningún detalle técnico sobre la confección del mapa ni sobre el método empleado para calcular el recorrido de la vía. Probablemente se ha empleado algún tipo de algoritmo de cálculo de trayectoria óptima entre dos puntos atendiendo al criterio de inclinación mínima.

El siguiente gráfico muestra cómo, partiendo del mapa mencionado anteriormente, los investigadores han procedido al trazado de las curvas de nivel y han dibujado su propuesta de trayectoria óptima:

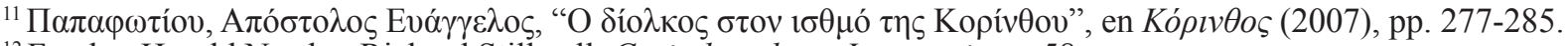

${ }^{12}$ Fowler, Harold North y Richard Stillwell, Corinth, volume I... op. cit., p. 58.
} 
Figura 17. Mapa de partida, con las cotas de las curvas de nivel marcadas.

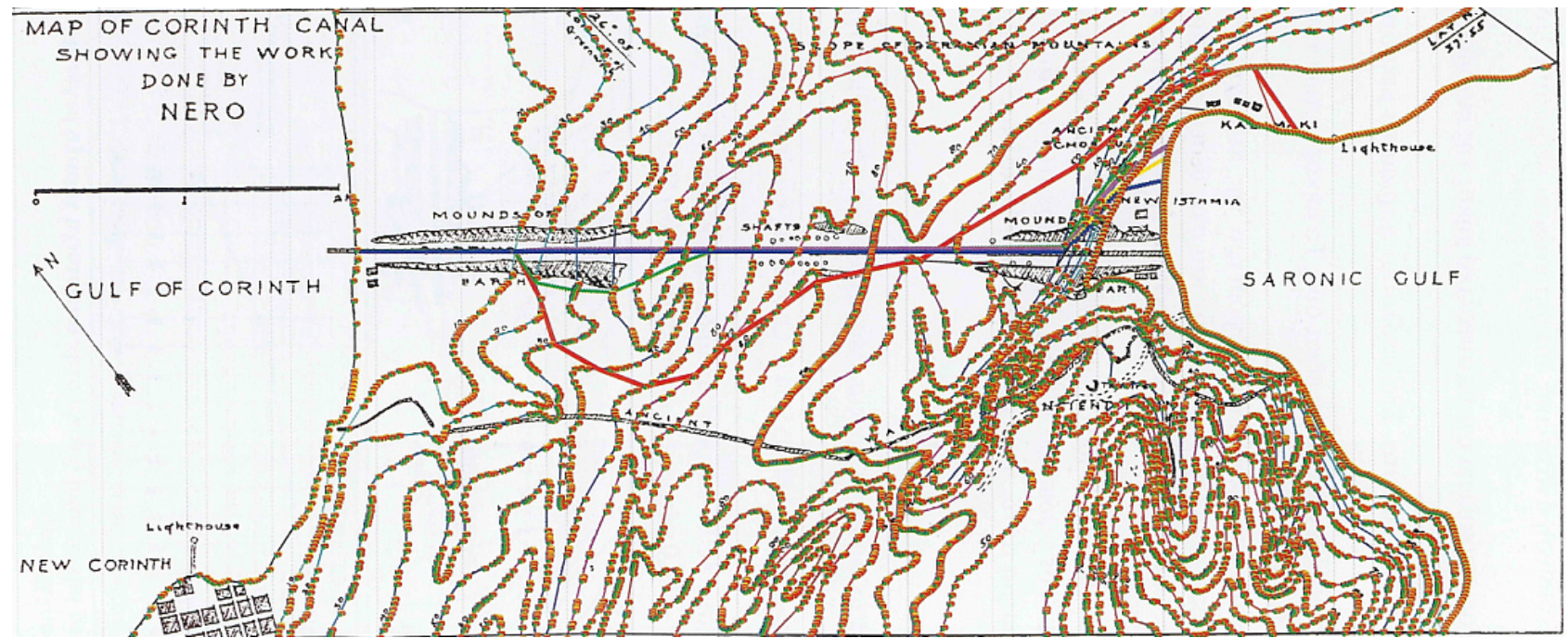

Fuente: p. 280.

Figura 18. Trayectoria propuesta por Apóstolos Papafotíou (p. 284).

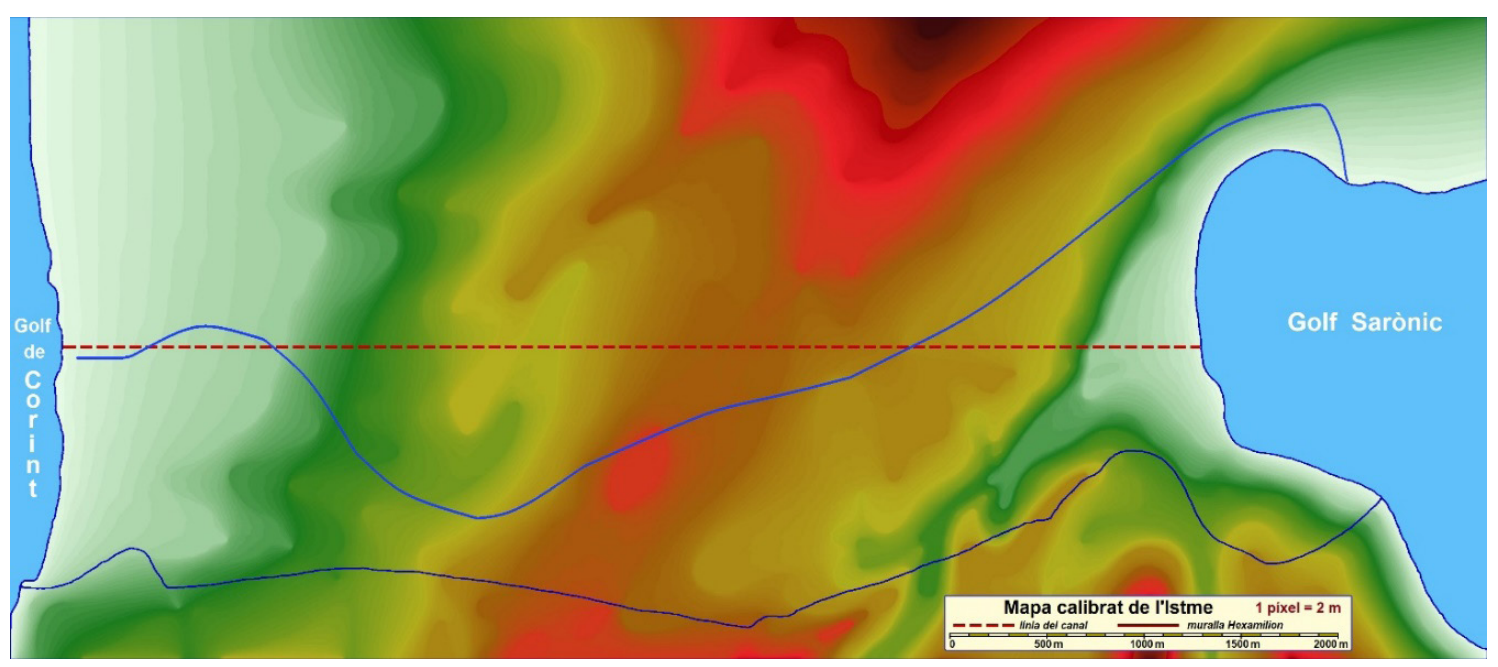

Fuente: elaboración propia.

Figura 19. Sección transversal de la propuesta de Apostolos Papafotíou.

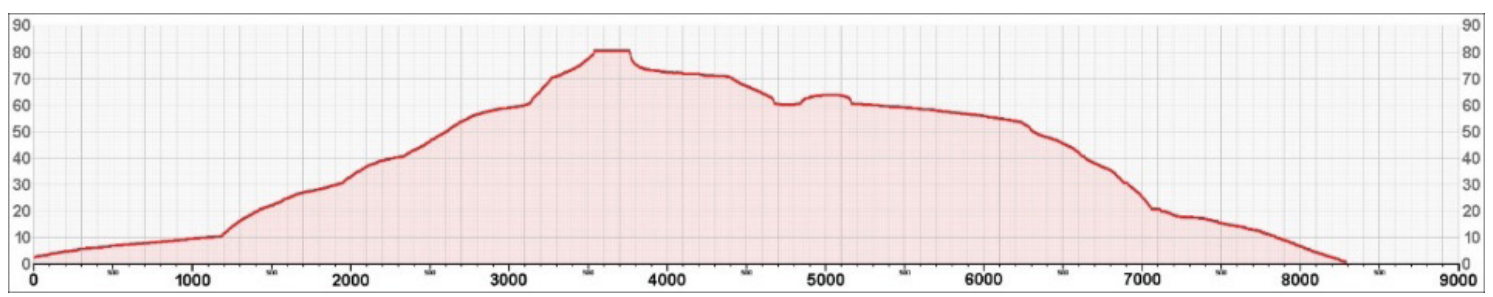

Fuente: elaboración propia. 
Aunque el autor parece haber encargado el apartado técnico del estudio del relieve del Istmo a una oficina especializada en Sistemas de Información Geográfica (SIG), la ruta propuesta es, con mucha diferencia, la peor que hemos analizado. No solo es la más larga y la que requiere más energía en términos de fuerza máxima aplicada y trabajo total, sino que, además, presenta fortísimas pendientes. Sin embargo, el autor remarca reiteradamente su idoneidad y el hecho de que en ningún caso supere el $3 \%$ de desnivel, lo que no es cierto.

Los resultados que aporta Papafotíou son realmente incomprensibles y no resisten el análisis más superficial. De hecho, es muy raro que los algoritmos de optimización de ruta hagan pasar su propuesta por la cota más alta del centro del Istmo $(80 \mathrm{~m})$. Solo observando la ruta trazada en nuestro mapa calibrado (fig. 18) y con el relieve coloreado se ve a simple vista que el recorrido no se adapta al terreno. Como Walter Werner, Papafotíou aporta un trazado del Díolkos que presenta una amplia curva por el Peloponeso y se acerca a la muralla Hexamilion.

Punto a favor:

- Como en el caso anterior de Walter Werner, al pasar cerca de la muralla Hexamilion la propuesta de Papafotíou permitiría la conexión con otros caminos entre los puertos principales Lequeo y Céncreas.

Puntos en contra:

- Trazado larguísimo (8289,31 m) y muy abrupto, con fuertes pendientes que llegan a superar el $25 \%$ y lo hacen inviable. Como en el caso anterior, en la gráfica de la sección transversal (fig. 19) se observan repentinos cambios de pendientes por todo el recorrido, así como el paso por la cota más alta del Istmo.

- La fuerza necesaria para desplazar una tonelada en los tramos más empinados es muy elevada: 2753 N. El trabajo total necesario por tonelada a lo largo del recorrido es el más elevado de todas las propuestas (3934287 J).

- En el centro del Istmo, la ruta propuesta pasa por la cota más alta $(80 \mathrm{~m})$.

\subsection{Propuesta de David Pettegrew (2011) $)^{13}$}

David K. Pettegrewes un profesor de Historia y Arqueología de la universidad cristiana privada Messiah College de Mechanicsburg, Pensilvania. Se trata de un experimentado investigador que ha dirigido excavaciones arqueológicas en Estados Unidos, Grecia y Chipre, y que ha escrito artículos y libros sobre varias ciudades antiguas del ámbito grecorromano. Personalmente, tuvimos la oportunidad de coincidir con él en junio de 2019 en Corinto donde pudimos visitar juntos los tramos conocidos del Díolkos e intercambiar opiniones sobre el tema. En su artículo "The Diolkos of Corinth", de 2011, este autor propone un trazado para el Díolkos

\footnotetext{
${ }^{13}$ Pettegrew, David K., "The Diolkos of Corinth", en American Journal of Archaeology, vol. 115, 4 (2011), p. 558. https://doi.org/10.3764/aja.115.4.0549
} 
bastante parecido al que hemos visto antes de Georges Raepsaet, pero que pasaría por debajo del canal actual.

Figura 20. Trayectoria propuesta por David Pettegrew (p. 558).

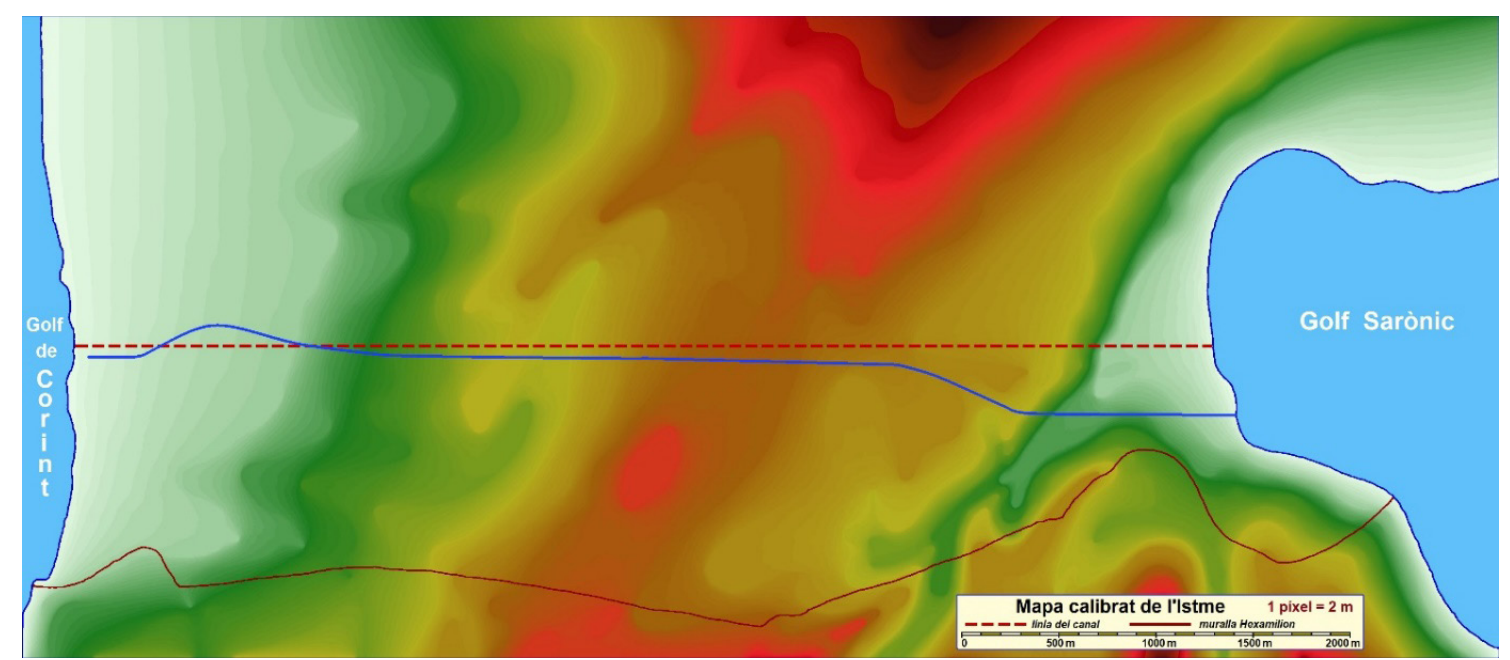

Fuente: elaboración propia.

Figura21. Sección transversal de este trayecto

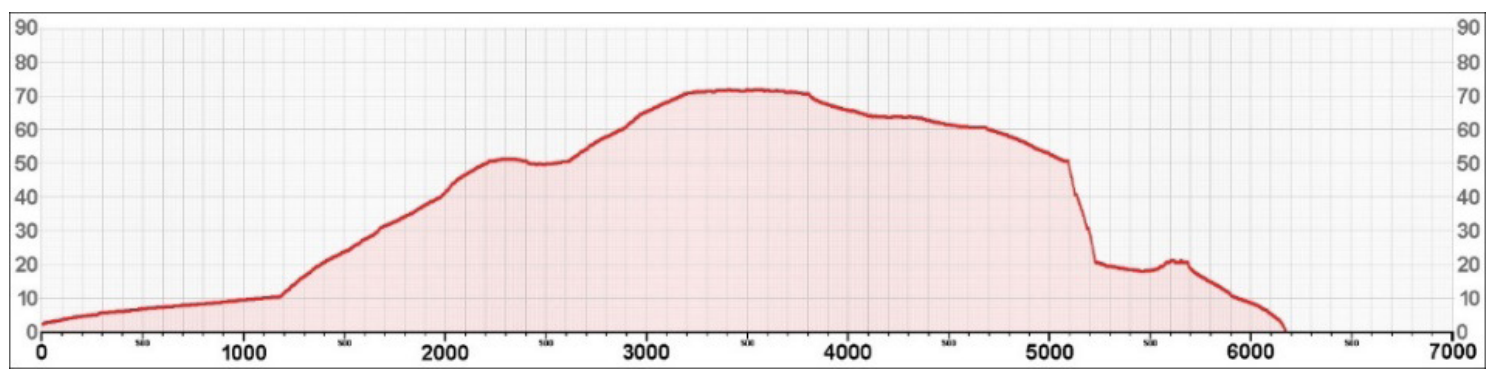

Fuente: elaboración propia.

Como en el caso de Georges Raepsaet, el hecho de pasar por la parte central del Istmo, cerca del canal actual hace que el recorrido sea bastante fácil y con pocas pendientes hasta llegar a las proximidades del Golfo Sarónico, donde se observan desniveles pronunciados que, a pesar de estar limitados a unas decenas de metros, superan el $30 \%$.

Punto a favor:

- Trayecto muy corto $(6171 \mathrm{~m}) \mathrm{y}$, por esta razón, económico en términos de trabajo total (31148983 J / Tm). Hay que remarcar que esta propuesta no llega al puerto de Skoinos, sino que finaliza al llegar a la costa del Golfo Sarónico. 
Puntos en contra:

- Trazado muy abrupto al acercarse al Golfo Sarónico con fuertes pendientes (superiores al $5 \%$ en el $7 \%$ del global de la ruta), y que superan el $15 \%$ en más de $100 \mathrm{~m}$ del trayecto. Estas fuertes pendientes hacen el trayecto inviable. En la gráfica de la sección transversal (fig. 21) podemos ver cómo, a partir de los $5100 \mathrm{~m}$ del recorrido, en tan solo $230 \mathrm{~m}$ el desnivel es de $30 \mathrm{~m}$.

- Una vez superada la sección conocida de la Escuela Militar de Ingeniería, con trazas del Díolkos que apuntan a su regreso hacia el Peloponeso, por debajo del Canal, el autor hace una propuesta de ruta completamente rectilínea, sin adaptarse mínimamente a las ondulaciones del terreno para minimizar las pendientes.

- Atraviesa los barrancos próximos al Golfo Sarónico de manera recta, afrontando difíciles pendientes.

- No finaliza en el puerto de Skoinos, como las otras propuestas.

\section{Cálculo de la trayectoria óptima}

Además de analizar las trayectorias propuestas por los estudiosos en la materia, hemos querido también elaborar una hipótesis de itinerario de la ruta con el fin de compararla con estas y ver si era posible mejorarlas. Abordamos los cálculos correspondientes sin ninguna idea preconcebida ni ninguna preferencia en particular. Nos hemos limitado a poner unas cuantas condiciones sencillas al programa generador de trayectos y a analizar los resultados. Los principales requerimientos a la hora de elaborar los recorridos han sido:

- Emplear la ruta más fácil y segura posible. Esto implica escoger pendientes suaves, que minimizan el esfuerzo necesario para el transporte de las cargas a través de una ruta pavimentada, así como el trazado de grandes curvas para facilitar el transporte de naves de, como máximo, la longitud de un trirreme griego (36 m).

- Iniciar el trayecto en la parte final conocida ubicada cerca de la Escuela Militar de Ingeniería de Loutraki y finalizarlo en el Golfo Sarónico, en el antiguo puerto de Skoinos.

El programa implementa un generador de itinerarios basado en un algoritmo genético que funciona según los principios de la evolución y la selección natural de las especies:

- El generador inicia el primer ciclo creando 100 trayectorias al azar.

- Una vez evaluadas las rutas, las 10 mejores generan una "descendencia" de cinco "hijos" cada una, conservando los rasgos "paternos" en diversa medida. De este 
Pere García Ruiz, “El antiguo Díolkos de Corinto. Análisis de las propuestas...”

modo, partiendo de unos buenos candidatos, los itinerarios van evolucionando hasta convertirse en propuestas óptimas. Se trata, en términos de Biología evolutiva, de la supervivencia de los mejores adaptados, según los requerimientos técnicos que hemos implementado.

- Aparte de los trayectos que van evolucionando, en cada ciclo se generan también 50 nuevas rutas al azar que realimentan el sistema.

- Cuando se detecta un candidato óptimo, a partir del cual el programa lleva un cierto número de ciclos sin progresar, se guarda y se vuelve a reiniciar el proceso.

El programa trabajó sin parar durante una semana, tiempo en el que elaboró unas 110 propuestas de trayecto óptimo ${ }^{14}$. Lo que ha sido un poco sorprendente es el hecho de que todas ellas sin excepción se situaban mayoritariamente en la zona de la Grecia continental, por encima de la línea del canal, evitando así las máximas alturas del centro del Istmo. Ninguno de los itinerarios transitaba por la parte del Peloponeso, como había calculado la oficina técnica de Apóstolos Papafotíou o había propuesto Walter Werner.

De todas las rutas destacadas que nos proporcionó la aplicación informática elegimos la mejor en términos de facilidad de recorrido y de economía energética. Ni que decir tiene que nuestro resultado es una especulación puramente teórica, que hemos obtenido a partir de herramientas informáticas de cálculo de recorridos óptimos, y que no tiene por qué corresponder con la realidad. De todos modos, hasta que no aparezcan vestigios del antiguo Díolkos que nos permitan mejorar nuestros criterios de búsqueda, o bien que alguien encuentre un camino más llano y económico en términos de esfuerzo, pensamos que nuestra propuesta será la mejor disponible. De hecho, se trata del mejor itinerario que podríamos ofrecer al tirano Periandro si nos hubiera encargado en su época el proyecto de construcción de la vía.

\footnotetext{
${ }^{14}$ Programa realizado en lenguaje Python. Se ejecutó en un núcleo de un Intel Core i7-3630QM a 2.40GHz.
} 
Figura 22. Trayectoria óptima calculada.

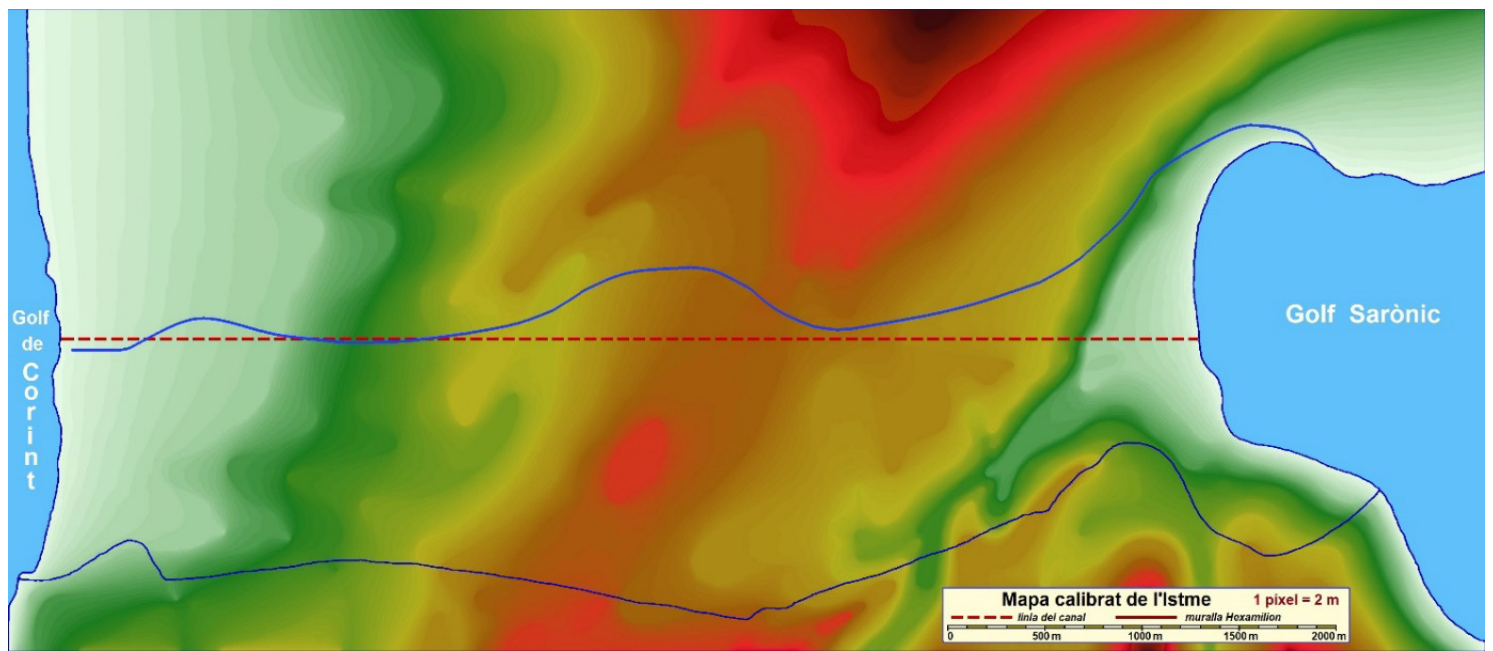

Fuente: elaboración propia.

Figura 23. Sección transversal de la trayectoria óptima.

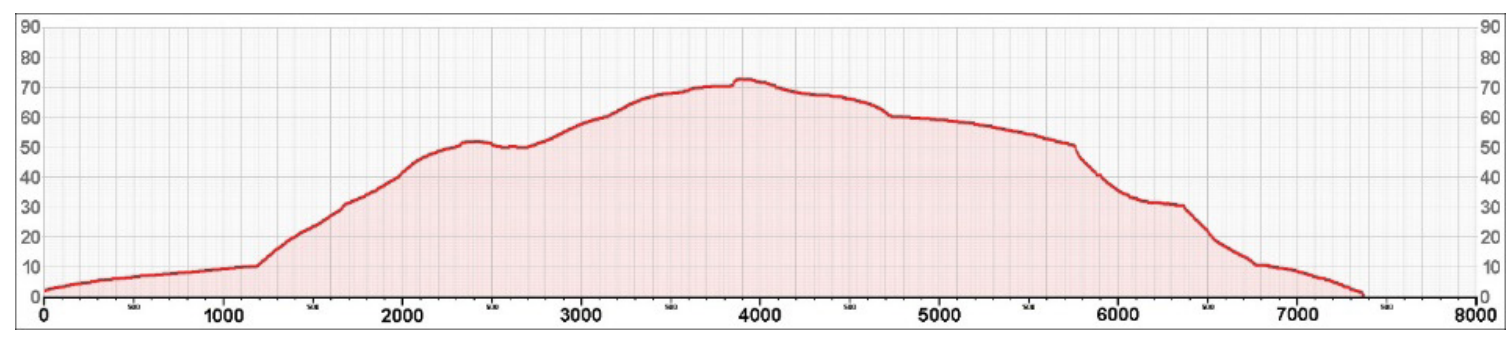

Fuente: elaboración propia.

Aparte de los comentarios anteriores sobre la conveniencia de la ruta calculada, expondremos a continuación sus ventajas e inconvenientes:

Puntos a favor:

- Trayecto de longitud razonable (7373 m), teniendo en cuenta las ondulaciones que sigue para adaptarse a la orografía. Además, debido a sus suaves pendientes, es muy económico en términos de trabajo total (3465388 J/Tm). La fuerza máxima que se debe aplicar para mover las cargas también es la más pequeña de todas las propuestas analizadas (1041.24 N/Tm). La bondad de la ruta también queda bien reflejada en la gráfica correspondiente a la sección transversal (fig. 23), que presenta transiciones suaves a lo largo de todo el recorrido.

- La longitud del itinerario calculado (39.85 estadios) es casi idéntica a la facilitada por Estrabón (Geografía, VIII, 2, 1) y que también figura en el Periplo de PseudoEscílax $^{15}: 40$ estadios.

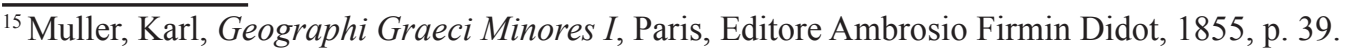


- Es bastante probable que el Díolkos fuera el resultado de la pavimentación y adecuación de un antiguo camino de conexión del Istmo que se remontara a los tiempos micénicos y que, en cuanto al trazado, siguiera sus mismos criterios. La experiencia personal al recorrer los restos de caminos micénicos de la Argólida nos sorprendió en su momento por la facilidad del trayecto entre colinas, adaptándose a las ondulaciones del terreno. Se evitaban los trayectos rectos para ahorrar esfuerzos en las pendientes.

- Atraviesa los barrancos próximos al Golfo Sarónico de manera oblicua, minimizando las pendientes, por una ruta por donde actualmente pasan la autopista y el ferrocarril. En esta sección es donde se encuentran las pendientes máximas, que no llegan al $8 \%$, y solamente en un pequeño intervalo de menos de $36 \mathrm{~m}$. Este valor, que resulta elevado en el caso de que el transporte se realizara mediante tracción animal, es perfectamente asumible por parte de la tripulación del trirreme, de unas 200 personas, que en estos tramos especialmente difíciles debería realizar un sobreesfuerzo puntual. De todas maneras, el 99,52\% del recorrido de nuestra propuesta presenta pendientes inferiores al $5 \%$.

Puntos en contra:

- Se trata de una especulación teórica y, hasta que no aparezcan nuevos datos, no se debe perder de vista este hecho. Como el resto de los periplos analizados, no hay ninguna evidencia de que sea realmente el itinerario real del Díolkos.

- A pesar de la robustez y el rigor del método empleado, los resultados dependen totalmente de la exactitud del relieve del Istmo a partir de los mapas consultados. Hemos partido de una cartografía inmediatamente anterior a la apertura del canal, que podría no corresponder exactamente con los cambios sufridos por el terreno a lo largo de los siglos y que, además, está ligeramente alterada por los depósitos de tierra provocados por las excavaciones de Nerón en el siglo I d. C.

\section{Conclusiones}

La verdadera dificultad de transportar barcos a lo largo de un itinerario terrestre viene definida sobre todo por dos características fundamentales: el esfuerzo físico que requiere el traslado de la nave siguiendo la ruta y las infraestructuras técnicas necesarias adaptadas al terreno por donde se desarrolla el transporte. En el presente escrito hemos analizado las propuestas de varios estudiosos sobre el camino teórico del Díolkos, así como hemos elaborado una hipótesis basada en algoritmos que minimizan las dificultades orográficas de la zona objeto de estudio. 
La demanda física de un trayecto depende, sobre todo, de la longitud del recorrido y de los correspondientes desniveles o pendientes, tanto de subida como de bajada, que hay que superar. Estas dos condiciones también están relacionadas con el tiempo necesario para completar el transporte. Así pues, el esfuerzo físico necesario y la percepción de dificultad son directamente proporcionales a la distancia del itinerario y los desniveles presentes a lo largo de sus intervalos. Aparte de esto, a la hora de evaluar un recorrido o bien proceder a su cálculo se deben tener en cuenta otros elementos u obstáculos que pueden comportar dificultades adicionales, como las curvas pronunciadas. En este aspecto debemos destacar que en el presente trabajo todas las rutas analizadas presentan amplios radios de curvatura, con espacio suficiente como para permitir el paso de un trirreme de $36 \mathrm{~m}$ sin maniobras complicadas de desplazamientos laterales.

A la hora de evaluar la idoneidad de un itinerario es importante tener en cuenta los diferentes desniveles a lo largo de la totalidad de su recorrido, y no solo la diferencia de altura entre el punto de inicio y el punto más alto del itinerario. En este sentido, llama la atención el hecho de que algunos autores como Walter Werner no lo tengan en cuenta, y se limiten a hablar de un gradiente de, como mucho, $1,37 \%{ }^{16}$, valor global que no indica la dificultad real de ciertas pendientes a superar en varios tramos de las rutas analizadas.

También nos ha sorprendido que una propuesta de recorrido teóricamente óptima como la de Apóstolos Papafotíou destacara por su mal resultado al analizarla con nuestras herramientas. A pesar de haber sido elaborada a partir de algoritmos de optimización de rutas, al trasladarla a nuestro mapa calibrado del Istmo ya se ve a simple vista que no se ajusta a los criterios mencionados por el autor, que manifiesta que sus pendientes no superan el $3 \%$.

En cuanto a las otras propuestas, pensamos que son muy interesantes, aunque deberíamos desconfiar de los itinerarios demasiado dilatados, como la ruta excesivamente larga por el Peloponeso de Walter Werner, o los trayectos completamente rectos (Raepsaet y Pettegrew), que no se adaptan a la orografía.

Un aspecto que ningún investigador ha tenido en cuenta a la hora de elaborar una ruta viable para la sección desconocida del Díolkos es cómo quedó afectado su trazado tras el intento de Nerón de abrir el Istmo. Aunque Papafotíou lo niega ${ }^{17}$, es muy probable que una pequeña parte de la ruta quedara seriamente dañada tras las excavaciones llevadas a cabo durante el principado de Nerón, en el año 67 d. C. Esto afecta tanto a la parte conocida del Díolkos como al tramo final cercano al Golfo Sarónico. De todas las propuestas analizadas, solo la de Walter Werner atraviesa esta última zona en su camino hacia el puerto de Skoinos, el resto queda al margen.

Esta cuestión no es trivial, ya que, según las fuentes históricas, los tránsitos documentados de barcos a través del Díolkos no llegan más allá del año 30 a. C, en que una flota de Octavio Augusto fue transportada por esta vía en una acción de persecución de la armada de Marco

\footnotetext{
${ }^{16}$ Werner, Walter, “The Largest Ship... op. cit., p.109.

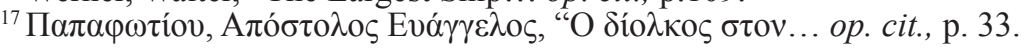


Antonio $^{18}$. Al parecer, en época imperial romana es bastante probable que el Díolkos cayera en desuso, al menos para el tráfico de naves a través del Istmo. El siguiente y último testigo de paso de barcos proviene de fuentes bizantinas como JorgeFranza ${ }^{19}$, está datado hacia finales del siglo IX y, según autores como David Pettegrew, es dudoso que se llevara a cabo ${ }^{20}$.

Para finalizar, no hace falta decir que si en el futuro se encontrara algún indicio, por pequeño que fuera, del recorrido del Díolkos, esto podría ayudar a descartar algunas hipótesis, al tiempo que contribuiría a la mejora de los cálculos del trazado óptimo, que debería ajustarse a los hallazgos correspondientes.

8. Anexo. Datos técnicos del análisis de las trayectorias

\subsection{Trazado conocido de la vía}

Distancia de la trayectoria: $1066.93 \mathrm{~m}=\mathbf{5 . 7 7}$ estadios. Trabajo total: $\mathbf{3 7 2 9 7 3 . 7 9} \mathbf{~ J} / \mathbf{T m}$ Fuerza máxima: 425.30 N/Tm Fuerza mínima: 341.75 N/Tm. Fuerza media: 349.58 N/ $\mathrm{Tm}$

Altura máxima: 9.29 m. Altura mínima: 1.74 m. Pendiente ascendiente máxima: 1.48 \% Pendiente ascendiente media: $0.71 \%-1066.93 \mathrm{~m}$

Intervalos del recorrido con pendientes: inferior al 3 \%: 1066.93 m (100.00 \%)

\subsection{Propuesta de Georges Raepsaet (1993)}

Distancia de la trayectoria: $6297.13 \mathrm{~m}=\mathbf{3 4 . 0 4}$ estadios. Trabajo total: $\mathbf{3 1 6 9 0 4 9 . 7 6} \mathbf{J} / \mathbf{T m}$ Fuerza máxima: 1706 N/Tm Fuerza mínima: 280 N/Tm Fuerza media: 503 N/Tm Altura máxima: $71.56 \mathrm{~m}$ Altura mínima: $0.00 \mathrm{~m}$ Pendiente máxima: $14.58 \%$ Pendiente ascendiente máxima: 4.78 \% Pendiente descendiente máxima: -14.58 \% Pendiente ascendiente media: $2.14 \%$ Pendiente descendiente media: $2.43 \%$

\section{Pendientes:}

inferior al $3 \%$ : $4755.31 \mathrm{~m} 75.52 \%$

entre 3 y $5 \%$ : $1228.71 \mathrm{~m} 19.51 \% \_<5 \%: 5984.02 \mathrm{~m} 95.03 \%$

\footnotetext{
${ }^{18}$ Cf. Dión Cassio, Historia Romana, LI, 5, 1-3.

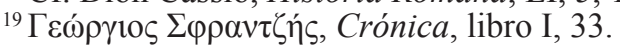

${ }^{20}$ Pettegrew, David K., "Niketas Ooryphas Drags his Fleet: Portaging the Corinthian Isthmus in 872 AD", en Annual meeting of the Archaeological Institute of America, San Antonio, TX, January, 2011.
} 
entre 5 y $10 \%$ : $188.59 \mathrm{~m} 2.99 \%$

entre 10 y $15 \%$ : $124.51 \mathrm{~m} 1.98 \%$ $5<15 \%: 313.10$ m $4.97 \%$

\subsection{Propuesta de Walter Werner (1997)}

Distancia de la trayectoria: $7852.33 \mathrm{~m}=\mathbf{4 2 . 4 5}$ estadios Trabajo total: $\mathbf{3 7 7 8 9 9 5 . 3 9} \mathbf{~} / \mathbf{T m}$ Fuerza máxima: 1581.82 N/Tm Fuerza mínima: 280.19 N/Tm Fuerza media: $481.26 \mathrm{~N} / \mathrm{Tm}$

Altura máxima: $74.86 \mathrm{~m}$ Altura mínima: $1.68 \mathrm{~m}$ Pendiente máxima: 13.30 \% Pendiente ascendiente máxima: $11.83 \%$ Pendiente descendiente máxima: $-13.30 \%$ Pendiente ascendiente media: $2.03 \%$ Pendiente descendiente media: $2.08 \%$

\section{Pendientes:}

inferior al $3 \%$ : $5699.05 \mathrm{~m} 72.58 \%$

entre 3 y $5 \%$ : 1828.24 m $23.28 \% \_<5 \%$ : 7527.29 m $95.86 \%$ entre 5 y $10 \%$ : $282.42 \mathrm{~m} 3.60 \%$ entre 10 y $15 \%$ : 42.63 m $0.54 \%$ 5<15\%: 325.04 m $4.14 \%$

\subsection{Propuesta de Apóstolos Papafotíou (2007)}

Distancia de la trayectoria: $8289.31 \mathrm{~m}=\mathbf{4 4 . 8 1}$ estadios Trabajo total: $\mathbf{3 9 3 4 2 8 6 . 9 4} \mathbf{~ J} / \mathbf{T m}$ Fuerza máxima: 2752.84 N/Tm Fuerza mínima: 280.19 N/Tm Fuerza media: $474.62 \mathrm{~N} / \mathrm{Tm}$

Altura máxima: $80.00 \mathrm{~m}$ Altura mínima: $0.23 \mathrm{~m}$ Pendiente máxima: $25.31 \%$ Pendiente ascendiente máxima: $6.29 \%$ Pendiente descendiente máxima: -25.31\% Pendiente ascendiente media: $2.13 \%$ Pendiente descendiente media: $1.86 \%$

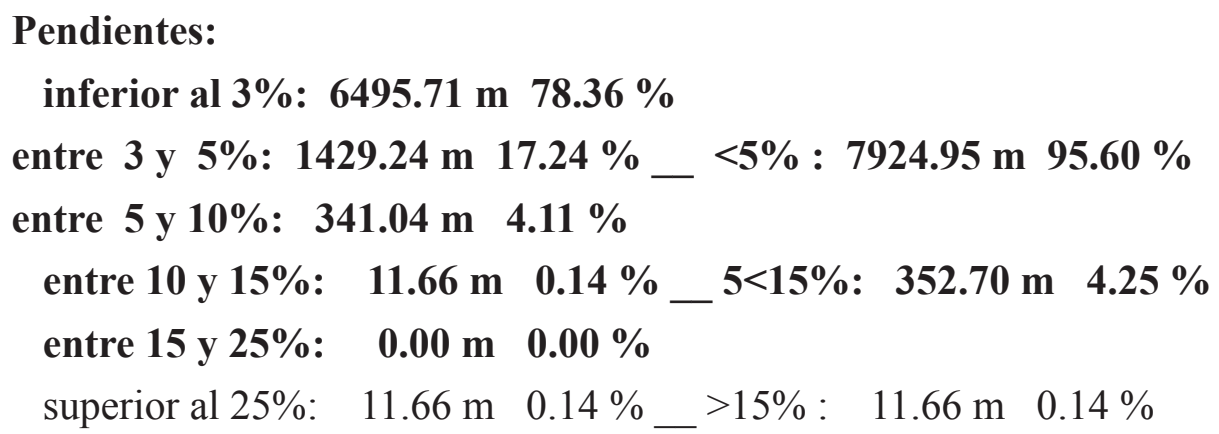


8.5. Propuesta de David Pettegrew (2011)

Distancia de la trayectoria: $6170.61 \mathrm{~m}=\mathbf{3 3 . 3 5}$ estadios Trabajo total: $\mathbf{3 1 4 8 9 8 2 . 6 8} \mathbf{J} /$ Tm

Fuerza máxima: 3613 N/TmFuerza mínima: 280 N/Tm Fuerza media: 510 N/Tm Altura máxima: $71.31 \mathrm{~m} \quad$ Altura mínima: $0.00 \mathrm{~m} \quad$ Pendiente máxima: $\mathbf{3 4 . 1 7}$ \% Pendiente ascendiente máxima: $\quad 6.08 \%$ Pendiente descendiente máxima: $-34.17 \%$ Pendiente ascendiente media: $1.94 \%$ Pendiente descendiente media: $2.96 \%$

Pendientes:

inferior al $3 \%$ : $3902.42 \mathrm{~m} \quad 63.24 \%$

entre 3 y $5 \%$ : 1840.45 m $29.83 \% \ldots<5 \%$ : $5742.87 \mathrm{~m} \mathrm{93.07 \%}$

entre 5 y $10 \%$ : $284.91 \mathrm{~m} 4.62 \%$

entre 10 y $15 \%$ : $24.00 \mathrm{~m} 0.39 \%$ _ $5<15 \%$ : $308.91 \mathrm{~m} 5.01 \%$

entre 15 y $25 \%$ : $82.83 \mathrm{~m} 1.34 \%$

superior al 25\%: $36.00 \mathrm{~m} 0.58 \% \ldots>15 \%$ : $118.83 \mathrm{~m} 1.93 \%$

\subsection{Cálculo de la trayectoria óptima}

Distancia de la trayectoria: $7373.16 \mathrm{~m}=\mathbf{3 9 . 8 5}$ estadios Trabajo total: $\mathbf{3 4 6 5 3 8 7 . 9 7} \mathbf{J} / \mathbf{T m}$ Fuerza máxima:1041.24 N/Tm Fuerza mínima:280.19 N/Tm Fuerzamedia: 470.00 N/ $\mathrm{Tm}$

Altura máxima: $72.37 \mathrm{~m}$ Altura mínima: $0.11 \mathrm{~m}$ Pendiente máxima: 7.77 \% Pendiente ascendiente máxima: $4.92 \%$ Pendiente descendiente máxima: $-7.77 \%$ Pendiente ascendiente media: $1.83 \%$ Pendiente descendiente media: $2.05 \%$

Pendientes:

inferior al $3 \%$ : $6498.95 \mathrm{~m} 88.14 \%$

entre 3 y $5 \%$ : 838.76 m $11.38 \% \ldots<5 \%$ : $7337.71 \mathrm{~m} 99.52 \%$

entre 5 y $10 \%$ : 35.46 m $0.48 \% \ldots 5<10 \%$ : 35.46 m $0.48 \%$ 